\title{
Chemical aging of $m$-xylene secondary organic aerosol: laboratory chamber study
}

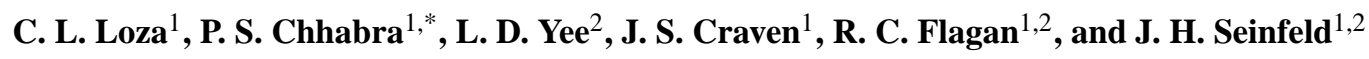 \\ ${ }^{1}$ Division of Chemistry and Chemical Engineering, California Institute of Technology, Pasadena, CA, USA \\ ${ }^{2}$ Division of Engineering and Applied Science, California Institute of Technology, Pasadena, CA, USA \\ *now at: Aerodyne Research, Inc., Billerica, MA, USA
}

Correspondence to: J. H. Seinfeld (seinfeld@ caltech.edu)

Received: 20 August 2011 - Published in Atmos. Chem. Phys. Discuss.: 7 September 2011

Revised: 8 December 2011 - Accepted: 20 December 2011 - Published: 3 January 2012

\begin{abstract}
Secondary organic aerosol (SOA) can reside in the atmosphere for a week or more. While its initial formation from the gas-phase oxidation of volatile organic compounds tends to take place in the first few hours after emission, SOA can continue to evolve chemically over its atmospheric lifetime. Simulating this chemical aging over an extended time in the laboratory has proven to be challenging. We present here a procedure for studying SOA aging in laboratory chambers that is applied to achieve $36 \mathrm{~h}$ of oxidation. The formation and evolution of SOA from the photooxidation of $m$-xylene under low- $\mathrm{NO}_{\mathrm{x}}$ conditions and in the presence of either neutral or acidic seed particles is studied. In SOA aging, increasing molecular functionalization leads to less volatile products and an increase in SOA mass, whereas gas- or particle-phase fragmentation chemistry results in more volatile products and a loss of SOA. The challenge is to discern from measured chamber variables the extent to which these processes are important for a given SOA system. In the experiments conducted, $m$-xylene SOA mass, calculated under the assumption of size-invariant particle composition, increased over the initial $12-13 \mathrm{~h}$ of photooxidation and decreased beyond that time, suggesting the existence of fragmentation chemistry. The oxidation of the SOA, as manifested in the O:C elemental ratio and fraction of organic ion detected at $\mathrm{m} / \mathrm{z}, 44$ measured by the Aerodyne aerosol mass spectrometer, increased continuously starting after $5 \mathrm{~h}$ of irradiation until the $36 \mathrm{~h}$ termination. This behavior is consistent with an initial period in which, as the mass of SOA increases, products of higher volatility partition to the aerosol phase, followed by an aging period in which gas- and particle-phase reaction products become increasingly more oxidized. When irradiation is stopped $12.4 \mathrm{~h}$ into one experiment, and $\mathrm{OH}$ generation ceases, minimal loss of SOA is ob-
\end{abstract}

served, indicating that the loss of SOA is either light- or OHinduced. Chemical ionization mass spectrometry measurements of low-volatility $m$-xylene oxidation products exhibit behavior indicative of continuous photooxidation chemistry. A condensed chemical mechanism of $m$-xylene oxidation under low- $\mathrm{NO}_{\mathrm{x}}$ conditions is capable of reproducing the general behavior of gas-phase evolution observed here. Moreover, order of magnitude analysis of the mechanism suggests that gas-phase $\mathrm{OH}$ reaction of low volatility SOA precursors is the dominant pathway of aging in the $m$-xylene system although $\mathrm{OH}$ reaction with particle surfaces cannot be ruled out. Finally, the effect of size-dependent particle composition and size-dependent particle wall loss rates on different particle wall loss correction methods is discussed.

\section{Introduction}

Organic aerosol (OA) constitutes $20-90 \%$ of all submicron particles in the atmosphere, and up to $80 \%$ of this is classified as secondary organic aerosol (SOA) (Zhang et al., 2007; Murphy et al., 2006). Aerosol particles in the atmosphere can have lifetimes of 5-12 days (Balkanski et al., 1993), during which they can undergo continuous physical and chemical processing, commonly called aging (Rudich et al., 2007). Laboratory experiments designed to study SOA formation typically have a duration of up to 1 day, during which all processes that cause ambient particle aging may not be captured. Chemical aging of SOA can affect gas-particle partitioning through processes such as vapor-phase oxidation of semivolatiles, heterogeneous oxidation, and reactions within the particle phase, e.g. oligomerization, that take place on 
a fairly long timescale (Kroll and Seinfeld, 2008; Hallquist et al., 2009).

Given the potentially large number of organic species in ambient particles, bulk chemical measurements are useful to describe the extent of oxidative aging of SOA. Using aerosol mass spectrometry, changes in O:C (elemental oxygen to carbon ratio) and $\mathrm{H}: \mathrm{C}$ (elemental hydrogen to carbon ratio) from high-resolution data and $f_{44}$ (ratio of mass-to-charge $(\mathrm{m} / \mathrm{z}$ ) 44 to total signal in the organic component mass spectrum) and $f_{43}$ (ratio of $m / z, 43$ to total signal in the organic component mass spectrum) have been reported for ambient and laboratory-generated particles. The dominant organic ion at $m / z, 43$ is $\mathrm{C}_{2} \mathrm{H}_{3} \mathrm{O}^{+}$, and the dominant organic ion at $\mathrm{m} / \mathrm{z}, 44$ is $\mathrm{CO}_{2}^{+}$. Ng et al. (2010) evaluated a number of aerosol oxidation data sets in the $f_{44}-f_{43}$ space and found that data for ambient OA tend to occupy a triangular region. As the OA becomes more oxidized, it tends to move from a region of lower $f_{44}$ and a wider range of $f_{43}$ at the base of the triangle toward the apex with higher $f_{44}$ and less variable $f_{43}$. Heald et al. (2010) used the Van Krevelen diagram to show that the $\mathrm{H}: \mathrm{C}$ and $\mathrm{O}: \mathrm{C}$ of total ambient $\mathrm{OA}$ tend to fall along a line with a slope of -1 , suggesting, on average, equal additions of carbonyl and alcohol moieties. More recently, $\mathrm{Ng}$ et al. (2011) determined a correlation between $f_{43}$ and $\mathrm{H}: \mathrm{C}$ and, combined with a correlation between $f_{44}$ and O:C (Aiken et al., 2008), mapped the triangular region in $f_{44}-f_{43}$ space onto the Van Krevelen diagram. They found that for ambient $\mathrm{OA}$ classified as oxygenated $\mathrm{OA}(\mathrm{OOA})$ and laboratory chamber-generated SOA the $\mathrm{H}: \mathrm{C}$ and $\mathrm{O}: \mathrm{C}$ evolution toward the apex of the triangle tends to fall along a line with a slope of -0.5 on a Van Krevelen diagram. This difference in slope between the two studies was attributed to the inclusion of primary OA in the study of Heald et al. The evolution of ambient OA can also be represented in terms of saturation concentration $\left(\mathrm{C}^{*}\right)$ and O:C (Jimenez et al., 2009). As the OA becomes more oxidized, $\mathrm{C}^{*}$ decreases and $\mathrm{O}: \mathrm{C}$ increases. In all three of these frameworks, the oxygen content of the organic aerosol increases upon aging.

Laboratory studies have been conducted to probe the mechanisms of chemical aging of SOA. In flow reactor experiments, which have much shorter residence times than chamber experiments, $\mathrm{OH}$ concentrations a few orders of magnitude higher than ambient concentrations are used to attain $\mathrm{OH}$ exposure similar to that of multiple days of atmospheric processing. Using a flow reactor, Kroll et al. (2009) found that for oxidation of squalane $\left(\mathrm{C}_{30} \mathrm{H}_{36}\right)$ particles, functionalization reactions (addition of polar functional groups) dominated at low $\mathrm{OH}$ exposure, and fragmentation reactions (scission of $\mathrm{C}-\mathrm{C}$ bonds in the carbon skeleton) dominated as $\mathrm{OH}$ exposure increased. They observed an O:C ratio of 0.45 after 35.8 squalene $\mathrm{OH}$ oxidation lifetimes. Lambe et al. (2011) also used a flow reactor to attain $\mathrm{OH}$ exposures equivalent to 1-20 days of atmospheric aging. Using a range of anthropogenic and biogenic SOA and oxidized primary organic aerosol (OPOA) precursors, they found that as $\mathrm{OH}$ ex- posure increased, the SOA and OPOA followed and extended the progression of ambient SOA in $f_{44}-f_{43}$ space, attaining values of $f_{44}$ higher than ambient SOA. The Van Krevelen diagram slope of the SOA and OPOA was indicative of carboxylic acid formation and carbon-carbon bond fragmentation. In chamber experiments of $16 \mathrm{~h}$ oxidant exposure, Qi et al. (2010) found that, starting after $2 \mathrm{~h}$ of $\mathrm{OH}$ exposure, the volatility of SOA generated from $m$-xylene and $\alpha$-pinene under high- $\mathrm{NO}_{\mathrm{x}}$ conditions decreased slowly for the remainder of the experiment. After this initial 2-h period, the O:C ratio for $m$-xylene SOA increased at a rate of $0.007 \mathrm{~h}^{-1}$; however, for $\alpha$-pinene SOA, the O:C ratio decreased at a rate of $0.003 \mathrm{~h}^{-1}$. Chhabra et al. (2010) observed increasing O:C for SOA formed from toluene, $m$-xylene, and naphthalene for irradiation times up to $12 \mathrm{~h}$. The most rapid increase in O:C occurred during the first hour of low- $\mathrm{NO}_{\mathrm{x}}$ toluene and $m$ xylene experiments and the first $4 \mathrm{~h}$ of low- $\mathrm{NO}_{\mathrm{x}}$ naphthalene experiments. Similarly to the results of Qi et al. (2010) that SOA from some precursors exhibits minute aging behavior, no change in O:C was observed for SOA from isoprene photooxidation or $\alpha$-pinene ozonolysis after initial SOA formation. Chhabra et al. (2011) extended the analysis of the SOA formed from the compounds studied in Chhabra et al. (2010) to assess their behavior in both $f_{44}-f_{43}$ space and Van Krevelen diagram representations. Although the SOA formed from the various precursors occupied different regions in each representation, most systems exhibited a progression similar to aging of ambient SOA.

In this work, we develop and apply to $m$-xylene SOA a procedure to extend to $36 \mathrm{~h}$ the experimental duration of a laboratory chamber operated as a batch reactor. Aromatic hydrocarbon emissions are an important contribution $(\sim 20$ $30 \%$ ) to the total volatile organic compounds in the urban atmosphere (Calvert et al., 2002). $m$-Xylene SOA yields (ratio of mass concentration of SOA formed to mass concentration of parent hydrocarbon reacted) have been measured previously for initial $m$-xylene concentrations of 10 to $180 \mathrm{ppb}$ and experimental durations up to $10 \mathrm{~h}$ ( $\mathrm{Ng}$ et al., 2007; Song et al., 2007). SOA yields for low- $\mathrm{NO}_{\mathrm{x}}$ conditions were found to be higher than those for high- $\mathrm{NO}_{\mathrm{x}}$ conditions. In addition, Chhabra et al. (2010) and Qi et al. (2010) observed changes in SOA chemical composition for up to $16 \mathrm{~h}$ of oxidation, indicating the potential of aging of $m$-xylene SOA over longer timescales. For a long duration experiment, the initial $m$ xylene concentration can be chosen to produce a sufficient amount of SOA to sample for the duration of the experiment yet remaining close to atmospherically relevant loadings, typically $0.1-20 \mu \mathrm{g} \mathrm{m}^{-3}$ (Shilling et al., 2009). In the present work, the total amount of SOA formed, its chemical composition, and the composition of the gas phase over $36 \mathrm{~h}$ of irradiation are evaluated to infer mechanisms of chemical aging of $m$-xylene SOA. For the first time, the effects of size-dependent particle composition on particle wall loss correction methods are discussed. 


\section{Materials and methods}

\subsection{Experimental setup}

Experiments were conducted in the Caltech dual $28-\mathrm{m}^{3}$ Teflon chambers. Details of the facilities are given elsewhere (Cocker et al., 2001; Keywood et al., 2004). Before each experiment, the chambers were flushed with dried, purified air for $>24 \mathrm{~h}$ until the particle number concentration $<50 \mathrm{~cm}^{-3}$ and the volume concentration $<0.1 \mu \mathrm{m}^{3} \mathrm{~cm}^{-3}$. Experiments were run under low- $\mathrm{NO}_{\mathrm{x}}$ conditions using hydrogen peroxide $\left(\mathrm{H}_{2} \mathrm{O}_{2}\right)$ as the $\mathrm{OH}$ source. With $\mathrm{H}_{2} \mathrm{O}_{2}$ it is possible to achieve a constant $\mathrm{OH}$ concentration for the duration of the experiments. $\mathrm{H}_{2} \mathrm{O}_{2}$ was injected into the chamber by evaporating $280 \mu \mathrm{l}$ of $50 \% \mathrm{wt}$ aqueous solution into the chamber with $51 \mathrm{~min}^{-1}$ of purified air. Seed particles were injected by atomizing a $0.015 \mathrm{M}$ aqueous ammonium sulfate (AS) solution for neutral seed and a $0.03 \mathrm{M}$ aqueous magnesium sulfate with $0.03 \mathrm{M}$ sulfuric acid (MS + SA) solution for acidic seed. $m$-Xylene (Sigma Aldrich, $99+\%$ ) was introduced into the chamber by injecting the volume of the liquid hydrocarbon required to obtain a concentration of $30 \mathrm{ppb}$ into a glass bulb, and the vapor was carried into the chamber with $51 \mathrm{~min}^{-1}$ of purified air. The chamber contents were allowed to mix for $1 \mathrm{~h}$ before beginning irradiation.

A suite of instruments was used to study the evolution of the gas and particle phases. $m$-Xylene was measured using a gas chromatograph with flame ionization detector (GC/FID, Agilent $6890 \mathrm{~N}$ ), equipped with a HP-5 column $(15 \mathrm{~m} \times 0.53 \mathrm{~mm}$ ID $\times 1.5 \mu \mathrm{m}$ thickness, Hewlett Packard). Reactive intermediates and $\mathrm{H}_{2} \mathrm{O}_{2}$ were continuously monitored using a custom-modified Varian 1200 triple-quadrupole chemical ionization mass spectrometer (CIMS). Details of operation can be found elsewhere (Crounse et al., 2006; Paulot et al., 2009; St. Clair et al., 2010). The CIMS was operated in negative mode in which $\mathrm{CF}_{3} \mathrm{O}^{-}$is used as the reagent ion. $\mathrm{CF}_{3} \mathrm{O}^{-}$clusters with the analyte, forming ions at $\mathrm{m} / \mathrm{z} \mathrm{MW}+85\left(\mathrm{R} \cdot \mathrm{CF}_{3} \mathrm{O}^{-}\right)$, or, with more acidic species, at $m / z \mathrm{MW}+19\left(\mathrm{HF} \cdot \mathrm{R}_{-\mathrm{H}}^{-}\right)$. Relative humidity $(\mathrm{RH})$, temperature, $\mathrm{NO}, \mathrm{NO}_{\mathrm{x}}$, and $\mathrm{O}_{3}$ were continuously monitored. The RH of the chamber was $<5 \%$. The initial chamber temperature was $\sim 19^{\circ} \mathrm{C}$; however, heating from the blacklights caused a rise in temperature of approximately $5^{\circ} \mathrm{C}$. NO and $\mathrm{NO}_{\mathrm{x}}$ concentrations were below the $2 \mathrm{ppb}$ detection limit of the instrument, and initial $\mathrm{O}_{3}$ concentration was $2 \mathrm{ppb}$.

Aerosol size distribution and number concentration were measured continuously using a differential mobility analyzer (DMA, TSI, 3081) coupled to a condensation particle counter (CPC, TSI, 3760), henceforth referred to as the DMA. Real-time particle mass spectra were collected continuously by an Aerodyne High Resolution Time-of-Flight Aerosol Mass Spectrometer (DeCarlo et al., 2006; Canagaratna et al., 2007), henceforth referred to as the AMS. The AMS switched once every minute between the high resolution 'W-mode' and the lower resolution, higher sensitivity
"V-mode". "V-mode" data were analyzed using a fragmentation table to separate sulfate, ammonium, and organic spectra and to time-trace specific $m / z$ ratios. "V-mode" and "Wmode" data were analyzed using a separate high-resolution spectra toolbox known as PIKA to determine the chemical formulas contributing to distinct $\mathrm{m} / \mathrm{z}$ ratios (DeCarlo et al., 2006). The signals of organic ions below $\mathrm{m} / z 119$ were used to calculate elemental ratios. The ratio of particle-phase $\mathrm{CO}^{+}$ to $\mathrm{CO}_{2}^{+}$was approximately equal to 1 , and the contribution of $\mathrm{CO}^{+}$to the organic signal was estimated to equal that of particle-phase $\mathrm{CO}_{2}^{+}$. The intensities of water-derived ions $\left(\mathrm{H}_{2} \mathrm{O}^{+}, \mathrm{OH}^{+}\right.$, and $\left.\mathrm{O}^{+}\right)$were estimated from particle-phase $\mathrm{CO}_{2}^{+}$using the correlation suggested by Aiken et al. (2008). A relative ionization intensity of 1.4 was applied to organic ion signals. AMS data reported in this work are averaged over 10-min intervals.

\subsection{Aging experiment protocols}

The volume of the reactor limits the duration of experiments in a chamber operated in batch mode; when sampling with all instruments, nearly half of the chamber volume is depleted in $18 \mathrm{~h}$, at which point it is preferable to cease sampling due to deflation of the chamber. To achieve longer $\mathrm{OH}$ exposure times with all instruments sampling, sets of experiments were conducted with increasing duration and staggered instrument sampling. Instruments were grouped into two categories based upon their sampling schedule. Group I includes the AMS and a RH and temperature probe. Group II includes the DMA, the CIMS, the GC/FID, the $\mathrm{O}_{3}$ analyzer, and the $\mathrm{NO}_{\mathrm{x}}$ analyzer. All instruments were operated during initial injections before the onset of irradiation. Experimental time began at the onset of irradiation. First, two $18 \mathrm{~h}$ experiments were conducted with Group I and II instruments sampling for the entire duration to establish consistency in the gas and particle phases during separate experiments. Subsequent experiments of $24 \mathrm{~h}, 30 \mathrm{~h}$, and $36 \mathrm{~h}$ were conducted to achieve longer $\mathrm{OH}$ exposure. The instrument sampling schedule for all experiments is given in Table 1 . The entire set of 5 experiments was conducted in the same chamber to avoid any differences between chamber conditions that may arise between the dual chambers. For each of the Group II instruments, the data from all experiments were combined to track the evolution of species for the entire $36 \mathrm{~h}$ of $\mathrm{OH}$ exposure.

\subsection{Total SOA formation}

To determine the total SOA mass concentration in the chamber, $\Delta M_{\mathrm{o}}$, particle wall losses must be taken into account. The extent of interactions between particles deposited on the chamber walls and vapors in the chamber has not been determined completely; therefore, two limiting assumptions are used to bound this interaction. These limits have been described and applied to chamber experiments by Weitkamp et al. (2007) and Hildebrandt et al. (2009, 2011). In one 
Table 1. Experiment sampling conditions and instrument sampling protocol.

\begin{tabular}{ccccc}
\hline $\begin{array}{c}\text { Experiment } \\
\text { Type }\end{array}$ & $\begin{array}{c}\text { Duration } \\
(\mathrm{h})\end{array}$ & $\begin{array}{c}\text { Volume Removed } \\
\left(\mathrm{m}^{3}\right)\end{array}$ & \multicolumn{2}{c}{ Sampling hours } \\
Group I $^{a}$ & Group II \\
\hline Wall loss & 23 & 6.14 & N/A $^{c}$ & N/A \\
18 h aging & 18 & 7.92 & $0-18$ & $0-18$ \\
24 h aging & 24 & 3.60 & $0-24$ & $16-24$ \\
30 h aging & 30 & 3.63 & $0-30$ & $22-30$ \\
36 h aging & 36 & 3.66 & $0-36$ & $28-36$ \\
\hline
\end{tabular}

${ }^{a}$ Group I instruments: AMS, RH and temperature probe (total volumetric flow rate $=$ $0.084 \mathrm{~L} \mathrm{~min}^{-1}$ ).

${ }^{b}$ Group II instruments: DMA, CIMS, GC/FID, $\mathrm{O}_{3}$ analyzer, $\mathrm{NO}_{\mathrm{x}}$ analyzer (total volumetric flow rate $=7.25 \mathrm{~L} \mathrm{~min}^{-1}$ ).

${ }^{c}$ Instruments sampling: DMA, $\mathrm{O}_{3}$ analyzer, $\mathrm{NO}_{\mathrm{x}}$ analyzer, $\mathrm{RH}$ and temperature probe (total volumetric flow rate $=4.45 \mathrm{~L} \mathrm{~min}^{-1}$ ).

limit, particles deposited on the wall are assumed to cease interaction with suspended vapors after deposition. In this case, the amount of organic material in the deposited particles does not change after deposition, and these particles remain at the same size at which they deposited for the remainder of the experiment. In the other limit, particles on the wall are assumed to interact with vapors in the chamber after deposition as if they had remained suspended. Thus, in this case, the amount of organic material in the particles after deposition changes at the same rate as the amount of organic material in the suspended particles, and the deposited particles continue to change size throughout the remainder of the experiment. This limit is analogous in theory to that of a chamber without walls. In either limit, the material on the walls is added to that which remains suspended to obtain the total amount of SOA formed.

During particle growth, the organic mass fraction of the suspended particles increases. In the first limit, the organic mass fraction of deposited particles does not increase after deposition; therefore, this case produces a lower limit for $\Delta M_{0}$. In the second limit, deposited particles are assumed to continue growing; therefore, this case is an upper limit for $\Delta M_{\mathrm{o}}$. These two limits of wall loss corrected $\Delta M_{\mathrm{o}}$ will subsequently be referred to as the lower bound and upper bound, respectively.

The lower bound limit on $\Delta M_{\mathrm{o}}$ is calculated from the DMA suspended particle number distribution. For each size bin $i$ at each time step $j$, the particle number distribution deposited to the wall, $n_{\mathrm{w}, i j}$, is calculated using size-dependent wall loss rates, $\beta_{i}$ :

$n_{, \mathrm{w}, i j}=n_{\mathrm{s}, i j} \exp \left(\beta_{i} \Delta t\right)$

where $n_{\mathrm{s}, i j}$ is the suspended particle number distribution in size bin $i$ at time step $j$, and $\Delta t$ is the difference between time step $j$ and time step $j+1$. Wall loss rates were determined from calibration experiments performed prior to the start of the aging experiments (methods detailed in Keywood et al., 2004; $\mathrm{Ng}$ et al., 2007). The deposited particle number distribution is added to the suspended particle number distribution to give a wall-loss corrected number distribution, $n_{\text {tot }, i j}$, which is then converted to a volume concentration, $V_{\mathrm{tot}, j}$, assuming spherical particles:

$$
\begin{aligned}
n_{\mathrm{tot}, i j} & =n_{\mathrm{s}, i j}+n_{\mathrm{w}, i j} \\
V_{\mathrm{tot}, j} & =\sum_{i=1}^{m} \frac{n_{\mathrm{tot}, i j}}{D_{\mathrm{p}, i} \ln 10} \times\left(D_{\mathrm{p}, i+}-D_{\mathrm{p}, i-}\right) \times \frac{\pi}{6} D_{\mathrm{p}, i}^{3}
\end{aligned}
$$

where $m$ is the total number of size bins, $D_{\mathrm{p}, i+}$ is the upper limit diameter for size bin $i$, and $D_{\mathrm{p}, i-}$ is the lower limit diameter for size bin $i$. A factor of $\ln 10$ is necessary to convert from a log normal distribution. The initial seed volume concentration, $V_{\text {seed }}$, is subtracted from the wall-loss corrected volume concentration to give the volume concentration of SOA, $V_{\mathrm{o}, j}$. To convert to SOA mass, $\Delta M_{\mathrm{o}, j}$, the SOA volume concentration is multiplied by the SOA density, $\rho_{\text {org }}$ :

$\Delta M_{\mathrm{o}, j}=\rho_{\mathrm{org}}\left(V_{\mathrm{o}, j}-V_{\text {seed }}\right)$

For low- $\mathrm{NO}_{\mathrm{x}} m$-xylene SOA, $\rho_{\text {org }}=1.33 \mathrm{~g} \mathrm{~cm}^{-3}$ (Ng et al., 2007). It is possible that $\rho_{\text {org }}$ changes as particle age increases, but it was assumed to be constant for the present study, which is consistent with the findings of Qi et al. (2010).

Calculating the lower bound wall-loss corrected mass relies on having continuous number distributions, which were not available for the 24-h, 30-h, and 36-h experiments. To obtain a continuous number distribution, the number distributions for all experiments were combined. The DMA sampling schedule was designed to allow a 2-h overlap period between shorter and longer experiments (i.e. sampling for the 24-h experiment began at $16 \mathrm{~h}, 2 \mathrm{~h}$ prior to the endpoint of the 18-h experiment) to facilitate the comparison of data between shorter and longer experiments. The number distributions from each experiment were combined sequentially. During periods of overlap between two experiments, a weighted average of the number distribution in each size bin was taken giving higher weight to the shorter experiment at the beginning of the overlap period and higher weight to the longer experiment at the end of the overlap period.

Both the number distribution of the seed particles and the initial concentration of $m$-xylene affect the number distribution of the aerosol. In the 24-h experiment, the seed volume was lower than that for the other AS seed experiments (Table 2). Assuming that the SOA produced in this experiment was comparable to that in the other experiments, the suspended particle volume would be lower than that of the other AS seed experiments, and the number distribution would be too small to combine with those of the other AS experiments to obtain a continuous number distribution. Without the data from the 24-h experiment, no number distribution data were available between hours 18 and 22. Number distributions during those $4 \mathrm{~h}$ were calculated from the 18- and 30-h experiments by fitting an exponential function to the number 
Table 2. Experimental conditions and results.

\begin{tabular}{cccccc}
\hline Seed & $\begin{array}{c}\text { Duration } \\
(\mathrm{h})\end{array}$ & $\begin{array}{c}\text { Initial } m \text {-xylene } \\
(\mathrm{ppb})\end{array}$ & $\begin{array}{c}\text { Seed vol. } \\
\left(\mu \mathrm{m}^{3} \mathrm{~cm}^{-3}\right)\end{array}$ & $\begin{array}{c}\text { Final } m \text {-xylene } \\
(\mathrm{ppb})\end{array}$ & $\begin{array}{c}\text { Final } \Delta M_{\mathrm{O}}{ }^{a} \\
\left(\mu \mathrm{g} \mathrm{m}^{-3}\right)\end{array}$ \\
\hline AS & 18 & $32.2 \pm 0.7$ & $11.1 \pm 0.3$ & $2.46 \pm 0.66$ & $21.9 \pm 1.7$ \\
$\mathrm{AS}$ & 18 & $31.8 \pm 0.7$ & $12.3 \pm 0.3$ & $0.84 \pm 0.66$ & $24.7 \pm 1.9$ \\
$\mathrm{AS}$ & 24 & $29.2 \pm 0.7$ & $9.10 \pm 0.2$ & $<0.5$ & N/A \\
AS & 30 & $29.1 \pm 0.7$ & $12.3 \pm 0.4$ & $<0.5$ & N/A \\
AS & 36 & $28.7 \pm 0.7$ & $13.1 \pm 0.2$ & $<0.5$ & N/A \\
AS & $12+8^{b}$ & $25.0 \pm 0.6$ & $10.5 \pm 0.3$ & $2.1 \pm 0.6$ & $20.0 \pm 1.0$ \\
MS + SA & 18 & $32.9 \pm 0.7$ & $10.5 \pm 0.4$ & $1.94 \pm 0.66$ & $22.5 \pm 1.8$ \\
MS + SA & 18 & $32.4 \pm 0.7$ & $10.8 \pm 0.4$ & $1.15 \pm 0.66$ & $21.7 \pm 1.7$ \\
MS + SA & 24 & $32.5 \pm 0.7$ & $10.6 \pm 0.3$ & $<0.5$ & N/A \\
MS + SA & 30 & $29.6 \pm 0.7$ & $10.6 \pm 0.3$ & $<0.5$ & N/A \\
MS + SA & 36 & $30.0 \pm 0.7$ & $10.8 \pm 0.4$ & $<0.5$ & N/A \\
\hline
\end{tabular}

${ }^{a}$ Lower bound limit

${ }^{b} 12.4 \mathrm{~h}$ irradiated $+8 \mathrm{~h}$ dark

distribution in each size bin during hours 16-18 of the 18-h experiment and hours $22-24$ of the 30-h experiment and using the function to interpolate a number distribution at 4-min increments.

Throughout an experiment, the volume of the chamber decreases due to sampling, but the surface area of the walls remains the same. It is possible that the increasing surfacearea-to-volume ratio will increase the particle wall loss rates. The duration of a typical wall loss experiment is $18-24 \mathrm{~h}$, shorter than that of the longest aging experiments. The aging experiments were designed to minimize the amount of air sampled from the chamber. Although more instruments sample from the chamber during an aging experiment than during a wall loss calibration experiment, the volume of air removed during an aging experiment is comparable to that of a wall loss calibration experiment (Table 1).

To confirm that wall loss rates do not vary significantly as chamber volume decreases, an additional wall loss calibration experiment was performed in each chamber. These calibration experiments were conducted following the same protocols as a typical wall loss calibration; however, before AS seed aerosol was injected, approximately $8 \mathrm{~m}^{3}$ of air was removed from the chambers to simulate conditions found at the end of an $18 \mathrm{~h}$ experiment. The wall loss rates determined from these low-volume experiments were within the range of wall loss rates observed in the chambers since they were installed in 2009 (Fig. 1). Therefore, time-dependence of the wall loss rate constants was assumed to be negligible during these aging experiments.

The upper bound limit on $\Delta M_{\mathrm{o}}$ is calculated by combining the AMS and DMA data. The experiments in the present work use seed particles containing sulfate, and the only process that decreases sulfate concentration in the suspended phase is wall loss. The initial sulfate concentration is calculated from the DMA seed volume concentration. There

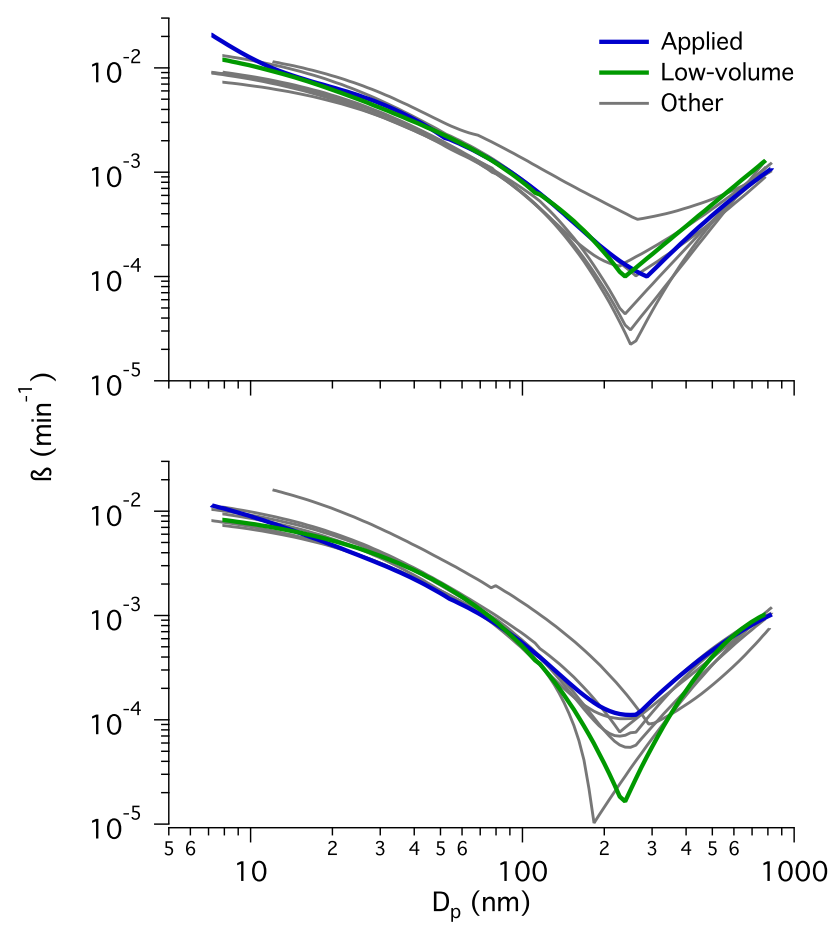

Fig. 1. Particle wall loss rates, $\beta$, measured in both chambers from September 2009 to August 2011. The top panel corresponds to near chamber, and the bottom panel corresponds to far chamber. The wall loss rates labeled "applied" were applied to the experiments reported in this manuscript. The wall loss rates labeled "low-volume" were calculated during a wall loss calibration experiment in which the initial chamber volume was decreased by $8 \mathrm{~m}^{3}$ to simulate conditions achieved after $18 \mathrm{~h}$ of sampling. The wall loss rates labeled "other" are those calculated from quarterly calibration experiments. 
is more uncertainty for the collection efficiency of seed particles in the AMS than in the DMA. Collection efficiency in the AMS increases as organic content of the particles increases, and because the seed particles do not contain organic material, they are more susceptible to bounce in the instrument and have a collection efficiency that is less than unity (Matthew et al., 2008). To calculate the mass of sulfate in the seed, $m_{\mathrm{SO}_{4}}$, the following equation is used:

$m_{\mathrm{SO}_{4}}=V_{\text {seed }} \rho_{\text {seed }} \frac{\mathrm{MW}_{\mathrm{SO}_{4}}}{\mathrm{MW}_{\text {seed }}}$

where $\rho_{\text {seed }}$ is the density of the seed particles, $\mathrm{MW}_{\mathrm{SO}_{4}}$ is the molecular weight of sulfate, and $\mathrm{MW}_{\text {seed }}$ is the molecular weight of the seed particles. For dry AS seed, $\rho_{\text {seed }}$ is $1.77 \mathrm{~g} \mathrm{~cm}^{-3}$. In the upper bound limit, both suspended and deposited particles gain or lose organic material at the same rate; therefore, the organic-to-sulfate ratio of all particles of the same size is the same, and this ratio is determined from unit mass resolution AMS data. High-resolution analysis of the dominant sulfate ions, $\mathrm{m} / \mathrm{z} 48$ and 64 , showed less than $1 \%$ contribution of organic signal to the total ion signal; therefore, organic contribution to the unit mass resolution sulfate signal was negligible. Differences in the organicto-sulfate ratio, $r_{\mathrm{OS}}$, between unit mass resolution and high resolution data are less than $5 \%$, except during the first $2 \mathrm{~h}$ of growth when they are more variable at lower organic loading. To obtain the SOA mass, $r_{\mathrm{OS}}$ is multiplied by the initial mass of sulfate in the seed particles:

$\Delta M_{\mathrm{O}}=m_{\mathrm{SO}_{4}} r_{\mathrm{OS}}$

This equation is valid if the organic-to-sulfate ratio does not vary with particle size or if particle wall loss rates are constant over the particle size range of interest. In the Caltech chambers, particle wall loss rates depend on particle size so the latter assumption is not valid. Depending on the condensation behavior of the SOA, $r_{\mathrm{OS}}$ may depend on particle size (Hildebrandt et al., 2009; Riipinen et al., 2011). For the present experiments, data were not available to determine the size dependence of $r_{\mathrm{OS}}$ of the particles. For the purpose of calculating the upper bound wall loss corrected organic mass, it is assumed that $r_{\mathrm{OS}}$ does not vary with particle size. The implications of this assumption will be discussed in Sect. 3.4.

\section{Results and discussion}

\subsection{SOA formation}

Two experiments with the same initial conditions and $18 \mathrm{~h}$ of irradiation were performed to assess the reproducibility of initial conditions and SOA production (Table 2). For both AS seed and MS + SA seed, similar concentrations of $m$ xylene reacted and $\Delta M_{\mathrm{O}}$ formed after $18 \mathrm{~h}$ of irradiation were achieved. Given the consistency between matched experiments, it was not necessary to sample for the entire duration of longer experiments. It was assumed that data collected during previous, shorter experiments are adequate to describe the same time period during longer experiments.

Figure 2 shows decay of $m$-xylene and $\Delta M_{\mathrm{o}}$ corrected for wall loss for both the upper and lower bound cases over 36 $\mathrm{h}$ of irradiation. The lower bound $\Delta M_{\mathrm{o}}$ and $m$-xylene data are a compilation of the 18-, 30-, and 36-h AS seed experiments (the 24-h experiment was omitted as noted earlier due to low seed particle volume), but the upper bound $\Delta M_{\mathrm{o}}$ data are from only the 36-h experiment because continuous data were available. The variation in the lower bound wall loss corrected mass concentration after peak growth is likely due to differences in number distributions during the 18-, 30-, and 36-h experiments. The peak in SOA formation occurs before all of the $m$-xylene has been reacted. For the lower bound case, $\Delta M_{\mathrm{O}}$ remains relatively stable after its peak, decreasing only slightly over $20 \mathrm{~h}$ of irradiation. For the upper bound case, $\Delta M_{\mathrm{o}}$ peaks at approximately the same time as in the lower bound case; however, there is a pronounced decay of $\Delta M_{\mathrm{o}}$ after the maximum is reached. Wall losses result in $43 \%$ of the total volume concentration of particles deposited on the wall for the lower bound case and $56 \%$ of $\Delta M_{\mathrm{o}}$ deposited on the wall for the upper bound case after 36 $\mathrm{h}$. The behavior of $\Delta M_{\mathrm{o}}$ after peak growth will be discussed in Sect. 3.3.

Throughout each experiment, the $\mathrm{OH}$ concentration was approximately $2.5 \times 10^{6} \mathrm{molec} \mathrm{cm}^{-3}$, as estimated from the decay of $m$-xylene and simulated by a photochemical model (see Appendix A). After $36 \mathrm{~h}$ of irradiation, $40 \%$ of the initial $4 \mathrm{ppm}$ of $\mathrm{H}_{2} \mathrm{O}_{2}$ injected into the chamber remained unreacted.

\subsection{SOA composition}

Figure 3 shows the evolution in the elemental oxygen-tocarbon ratio $(\mathrm{O}: \mathrm{C})$ of the suspended particles for all 5 of the AS seeded experiments. O:C values overlap for all of the experiments with different irradiation durations. $\mathrm{O}: \mathrm{C}$ decreases during the first $5 \mathrm{~h}$ of irradiation in all but the 36-h experiment. During the 36-h experiment, the sensitivity of the AMS sampling in W-mode was lower than that in the other aging experiments, which hindered the detection of initiallyformed SOA. The O:C calculated using V-mode data (not shown) decreasess during the first $5 \mathrm{~h}$ of irradiation for all 5 of the aging experiments. The dominant trend in $\mathrm{O}: \mathrm{C}$ begins after $5 \mathrm{~h}$. After this time, O:C gradually increases at an average rate of $0.0019 \mathrm{~h}^{-1}$ for the remainder of the irradiation period. The minimum in O:C occurs before the maximum $\Delta M_{\mathrm{o}}$ is reached.

The mass spectral parameter $f_{44}$ is commonly used to characterize SOA chemical composition. Aiken et al. (2008) determined a relationship between O:C and $f_{44}$ for ambient aerosol in Mexico City: $\mathrm{O}: \mathrm{C}=(3.82 \pm 0.05) \times f_{44}+$ $(0.0794 \pm 0.0070)$ for $f_{44}$ ranging from 0 to 0.25 . The SOA in the current set of experiments does not follow the same 


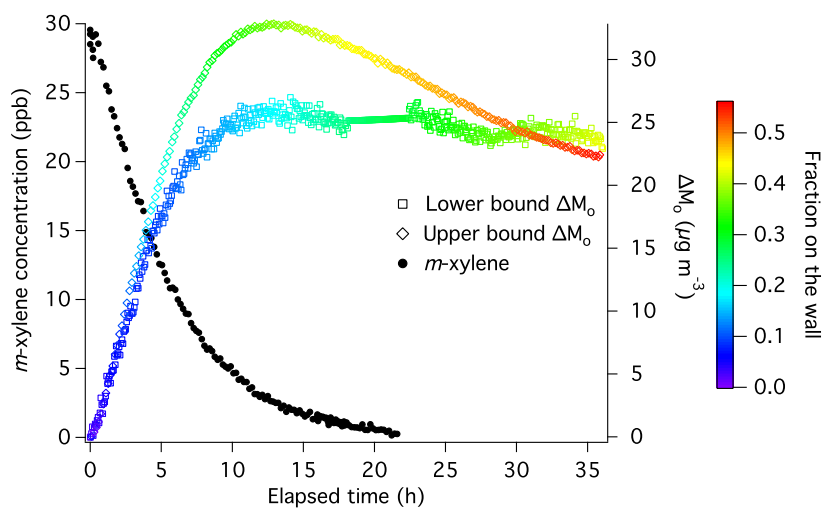

Fig. 2. SOA mass (right axis), corrected for particle wall losses, and $m$-xylene (left axis) for $36 \mathrm{~h}$ of $\mathrm{OH}$ exposure using AS seed. The lower bound $\Delta M_{\mathrm{O}}$ is calculated assuming that, once deposited, particles on the walls do not interact with gases in the chamber. The upper bound $\Delta M_{\mathrm{O}}$ assumes that, once deposited, particles continue to exhibit the same gas-particle partitioning behavior as suspended particles. The fraction on the wall for the lower bound is the ratio of particle volume on the wall to total particle volume, both suspended and deposited, and includes seed volume. The fraction on the wall for the upper bound is the ratio of organic mass concentration on the wall to the total organic mass concentration.

trend as the Mexico City SOA, and exhibits trendline of $\mathrm{O}: \mathrm{C}=(1.42 \pm 0.04) \times f_{44}+(0.439 \pm 0.005)$ over a range of 0.10 to 0.14 of $f_{44}$. Although the data for $m$-xylene SOA do not follow the same trendline as the Mexico City data, they lie within the scatter of the Mexico City data (Fig. 4). Using the same AMS instrument as the current study, Chhabra et al. (2010) found that the O:C and $f_{44}$ of SOA from aromatics, isoprene, and glyoxal did not lie along the trendline reported in Aiken et al., but the O:C and $f_{44}$ of SOA from $\alpha$-pinene and naphthalene did. In general, if $\mathrm{CO}_{2}^{+}$contributed most of the oxygen signal in the spectra, then the O:C and $f_{44}$ of the SOA more closely matched those predicted by the trendline from the Mexico City data. The correlation between $\mathrm{O}: \mathrm{C}$ and $f_{44}$ for $m$-xylene SOA in the present work differs from that of Lambe et al. (2011), who observed that $m$-xylene SOA follows the same trendline as the Mexico City data. The range of $f_{44}$ values observed by Lambe et al. is much larger than that in the present work, initial hydrocarbon loadings are higher, and $\mathrm{OH}$ exposure is $2-3$ times greater than the maximum $\mathrm{OH}$ exposure achieved in the present work $\left(3.2 \times 10^{11}\right.$ molec $\left.\mathrm{cm}^{-3} \mathrm{~s}\right)$. Any of these factors could contribute to the different correlations between $\mathrm{O}: \mathrm{C}$ and $f_{44}$. The factor most likely to explain the discrepancy between the correlation in the present work and that in Lambe et al. is the difference in $\mathrm{OH}$ exposure. At higher $\mathrm{OH}$ exposure, the SOA is likely to be more oxidized, and $\mathrm{CO}_{2}^{+}$ is likely to be a major contributor to the oxygen signal in the spectra.

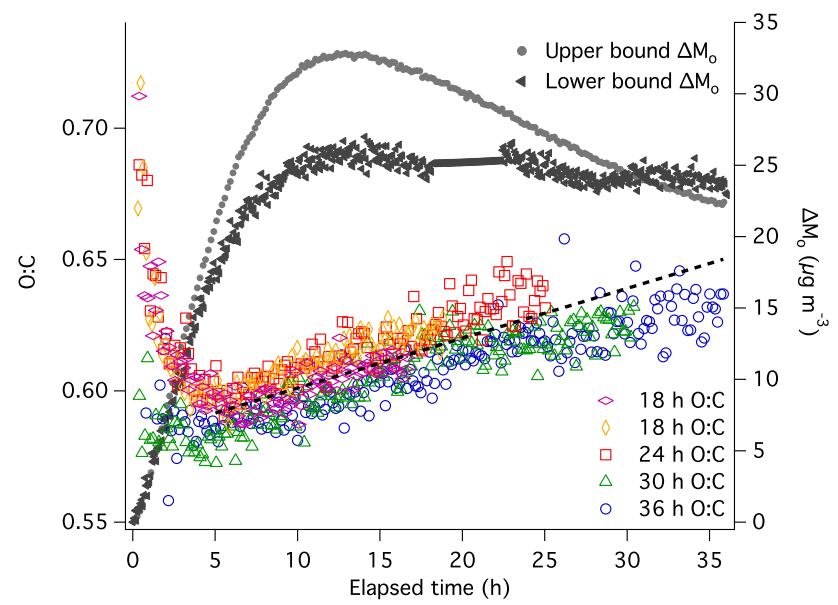

Fig. 3. SOA mass (right axis) and O:C elemental composition (left axis) over $36 \mathrm{~h}$ of $\mathrm{OH}$ exposure using AS seed. After hour 5, the $\mathrm{O}: \mathrm{C}$ increases at an average rate of $0.0019 \mathrm{~h}^{-1}$ (dashed line).

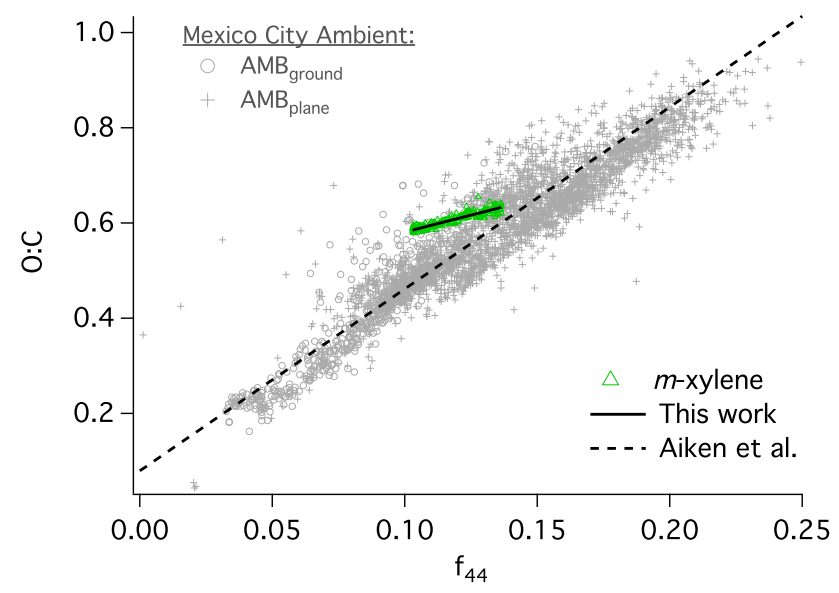

Fig. 4. Correlation of O:C with $f_{44}$ for SOA from $m$-xylene in the present study and Mexico City ambient aerosol from Aiken et al. (2008).

The evolution of $m$-xylene SOA is also represented in $f_{44}-$ $f_{43}$ space (Fig. 5). The change in $\mathrm{O}: \mathrm{C}$, derived from the correlation specific to $m$-xylene, is also shown. The marker size is a function of the concentration of suspended organics, normalized to suspended sulfate concentration to account for wall losses. Overall, low- $\mathrm{NO}_{\mathrm{x}} m$-xylene SOA exhibits higher $f_{43}$ than the typical range of ambient SOA observed by $\mathrm{Ng}$ et al. (2010) and lies to the right of the triangular region derived for ambient SOA. At the beginning of irradiation when the organic mass loading is small, the SOA has a higher $f_{44}$ and a lower $f_{43}$. As SOA continues to form, $f_{44}$ decreases and $f_{43}$ increases until approximately $5 \mathrm{~h}$ of irradiation, at which time the trends reverse. For the remaining duration of irradiation, $f_{44}$ increases and $f_{43}$ decreases, resulting in a progression of the SOA characteristic of the behavior of 


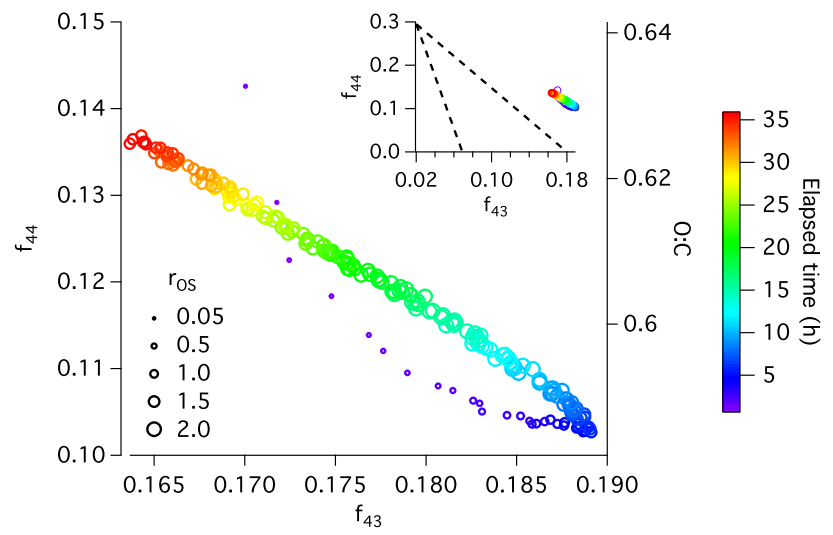

Fig. 5. Evolution of $f_{43}, f_{44}$, and $\mathrm{O}: \mathrm{C}$ for $36 \mathrm{~h}$ of $\mathrm{OH}$ exposure. This system lies to the right of the triangular region in which typical ambient aerosol resides, as shown by the dashed lines in the inset (Ng et al., 2010). Marker size denotes the organic-to-sulfate ratio, $r_{\mathrm{OS}}$, of suspended particles.

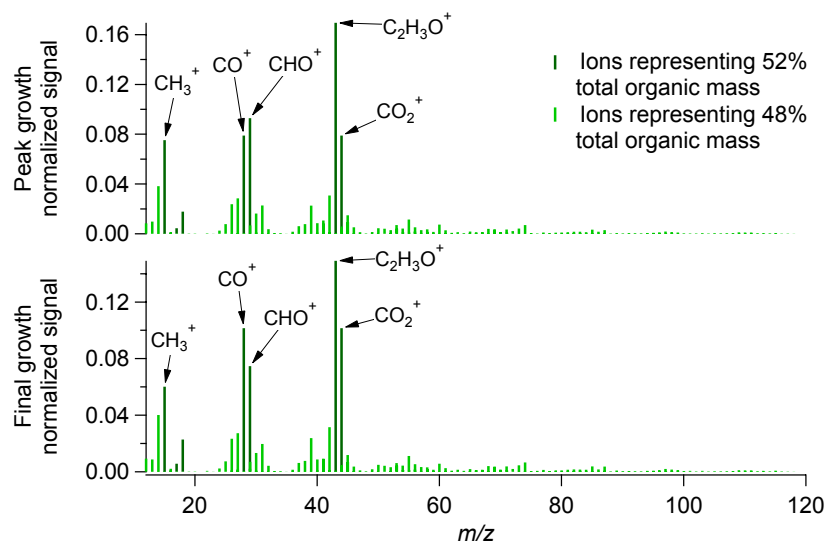

Fig. 6. Average AMS high-resolution organic mass spectra at the time of peak growth and at the end of the experiment (final growth) for the 36-h aging experiment. Prominent peaks are identified. The mass of $\mathrm{CO}^{+}$is estimated to equal that of $\mathrm{CO}_{2}^{+}$.

more-aged ambient SOA. The time at which the path reversal in $f_{44}-f_{43}$ space occurs is the same as that at which the minimum in O:C occurs. Curvature in $f_{44}-f_{43}$ space has been observed in other studies (Kroll et al., 2009; $\mathrm{Ng}$ et al., 2010; Chhabra et al., 2011; Lee et al., 2011; Lambe et al., 2011). Lambe et al. did not observe curvature in $f_{44}-f_{43}$ space for $m$-xylene SOA, and the curvature observed in the present study occurred for lower $\mathrm{OH}$ exposures than the lowest value attained by Lambe et al.. It is possible that the $\mathrm{OH}$ exposure levels used to form $m$-xylene SOA in Lambe et al. were too large to observe the curvature.

The high-resolution AMS mass spectra provide clues to the trends in $\mathrm{O}: \mathrm{C}, f_{44}$, and $f_{43}$. The average mass spectra at peak organic growth and at the end of the 36-h aging experiment are shown in Fig. 6. Figure 7 shows the time trends

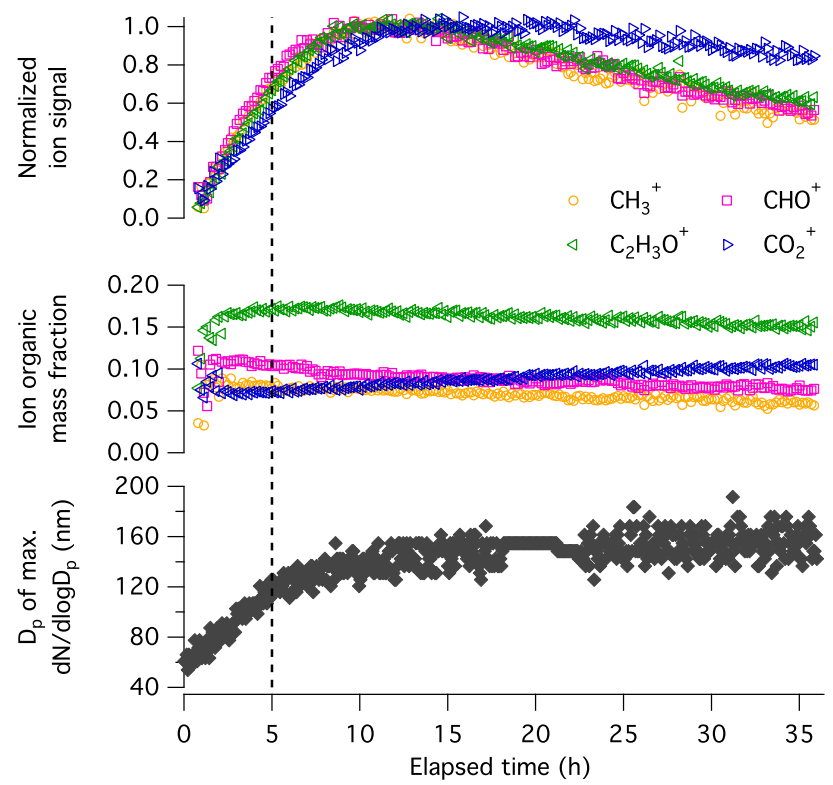

Fig. 7. Evolution of SOA chemical composition from highresolution AMS measurements and diameter of the maximum number distribution of suspended particles. In the top panel, the ion signal is normalized by sulfate to account for particle wall losses. The sulfate-normalized ion signal is then scaled by the average value at the peak concentration. The middle panel shows the fractional contribution of each ion to the total organic mass signal. A relative ionization efficiency of 1.4 is used when calculating the organic ion concentration. The dashed line at $5 \mathrm{~h}$ corresponds to the reversal in trend of $\mathrm{O}: \mathrm{C}$.

of the 4 dominant organic ions $\left(\mathrm{CH}_{3}^{+}, \mathrm{CHO}^{+}, \mathrm{C}_{2} \mathrm{H}_{3} \mathrm{O}^{+}\right.$, and $\mathrm{CO}_{2}^{+}$) in the aerosol mass spectra and the maximum of the suspended particle size distribution throughout $36 \mathrm{~h}$ of oxidation. Excluding $\mathrm{CO}_{2}^{+}$, these ions account for $30-35 \%$ of the total organic signal throughout the experiment. When organic $\mathrm{CO}_{2}^{+}$and the ions whose organic contributions are assumed to correlate with it $\left(\mathrm{CO}^{+}, \mathrm{H}_{2} \mathrm{O}^{+}, \mathrm{OH}^{+}\right.$, and $\left.\mathrm{O}^{+}\right)$are included, the mass fraction of the organic signal is approximately $52 \%$. In the top panel of Fig. 7, the time trends of the normalized, wall-loss corrected ion signals are shown. To obtain this, the ion signal was divided by the sulfate signal to correct for wall losses. The sulfate-normalized ion signal was then scaled by its average value at the peak concentration. In the middle panel, the fractional contribution of each ion to the total organic signal is shown. The bottom panel shows the particle diameter $\left(D_{\mathrm{p}}\right)$ of the maximum of the suspended particle size distribution. The most rapid change in $D_{\mathrm{p}}$ occurs during the first $5 \mathrm{~h}$ of irradiation. The amount of each of the 4 ions in the particles increases during this time (top panel). After $5 \mathrm{~h}, D_{\mathrm{p}}$ changes more slowly, and the contribution of each ion to the spectra begins to peak. $\mathrm{CHO}^{+}$reaches a maximum most quickly, followed by $\mathrm{CH}_{3}^{+}$and $\mathrm{C}_{2} \mathrm{H}_{3} \mathrm{O}^{+} . \mathrm{CO}_{2}^{+}$ peaks later than the other ions. After most of the ions peak, their contribution to the spectra decreases for the remainder 
of the experiment; however, the amount of $\mathrm{CO}_{2}^{+}$shows much less of a decrease, suggesting that compounds that contribute to the $\mathrm{CO}_{2}^{+}$signal have a lower tendency to be removed from the particles than those that contribute to the other ion signals.

Shortly after the onset of irradiation, $\mathrm{CO}_{2}^{+}$constitutes the largest fraction of the organic signal, likely from the condensation of low-volatility organics. As irradiation continues, the $\mathrm{CO}_{2}^{+}$fraction of the organic signal decreases as semivolatile material represented by the other ions, especially $\mathrm{C}_{2} \mathrm{H}_{3} \mathrm{O}^{+}$, begins to partition to the particles. Once the rate of particle growth slows, the fraction of $\mathrm{CO}_{2}^{+}$increases because the contribution of $\mathrm{CO}_{2}^{+}$to the mass spectra is still increasing, whereas the amounts of the other ions are beginning to stabilize and then decrease. The increase in the organic fraction of $\mathrm{CO}_{2}^{+}$continues throughout the duration of the experiment caused by a larger decrease in the amounts of the other ions in the particle mass spectra than $\mathrm{CO}_{2}^{+}$.

\subsection{Fate of SOA after peak growth}

After peak growth, a decrease in most of the major organic ions and the total organic mass is observed (Figs. 2 and 7). The magnitude of the decrease in $\Delta M_{\mathrm{O}}$ is much greater for the upper bound wall loss correction than that for the lower bound wall loss correction, suggesting that either the process causing the decrease in $\Delta M_{\mathrm{o}}$ has a larger effect on the upper bound wall loss case or that an incorrect assumption was made for one of the wall loss corrections. For the upper bound wall loss correction, $r_{\mathrm{OS}}$ was assumed to be constant such that the $r_{\mathrm{OS}}$ of the suspended particles was equivalent to that of the deposited particles. If this is not the case, the mass lost to the walls may be over- or underestimated. Implications of the size-dependence of $r_{\mathrm{OS}}$ on the upper and lower bound wall loss correction and its effects on the conclusions of the present section will be discussed in Sect. 3.4.

If the organic mass lost to the wall was correctly calculated for both upper and lower bound cases, a possible explanation for the decrease in $\Delta M_{\mathrm{o}}$ after peak growth is repartitioning of semivolatiles to the gas phase. As irradiation continues, semivolatiles in the gas phase can undergo reaction with $\mathrm{OH}$ or photolysis to form higher-volatility products, or they may be lost to the walls. As the concentration of a semivolatile in the gas phase decreases from fragmentation reactions or wall loss, repartitioning can occur to maintain gas-particle equilibrium. $\mathrm{OH}$ can also react with the particle surface, forming higher volatility fragmentation products that evaporate and decrease the particle organic mass. These processes are summarized in Fig. 8. Evaporation of semivolatiles is expected to have a greater effect on $\Delta M_{\mathrm{o}}$ in the upper bound limit because all particles are assumed to undergo gas-particle partitioning, opposed to only the suspended particles in the lower bound limit, thus a higher decrease in $\Delta M_{\mathrm{o}}$ should be expected in the upper bound limit.

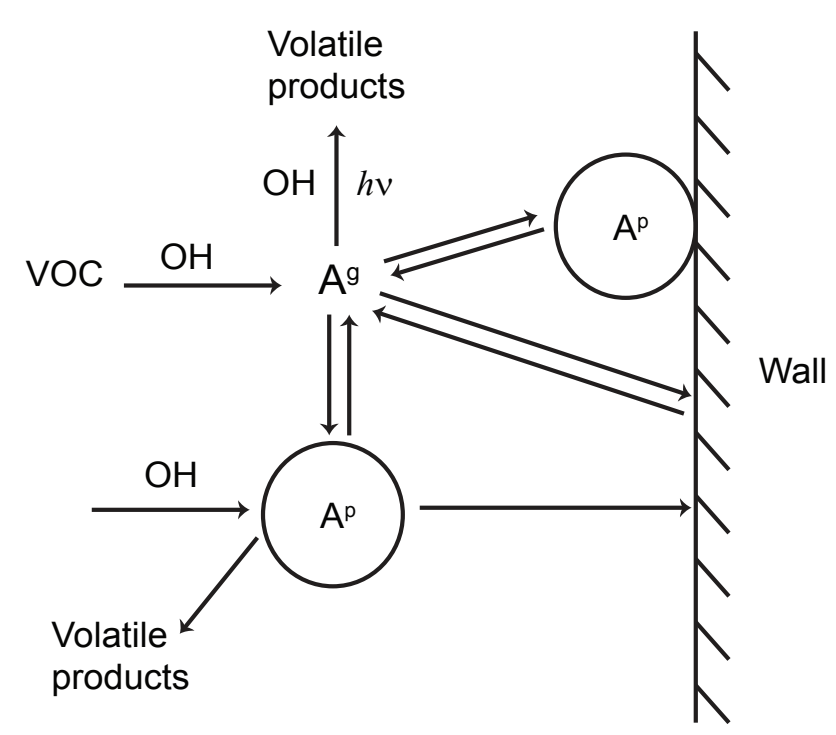

Fig. 8. Sources and sinks of a semivolatile gas-phase species, $A^{g}$, and particles containing the condensed semivolatile species, $\mathrm{A}^{\mathrm{p}}$, during SOA aging. We do not explicitly indicate in the sketch processes by which the particle-phase $\mathrm{A}^{\mathrm{p}}$ attains a semisolid state, greatly affecting continued exchange with the gas phase (Virtanen et al., 2010; Vaden et al., 2010, 2011; Shiraiwa et al., 2011).

Semivolatile species are expected to repartition from the particle phase more easily than low volatility species. This behavior is observed with the organic ions $\mathrm{C}_{2} \mathrm{H}_{3} \mathrm{O}^{+}$, characteristic of semivolatile oxygenated organic aerosol (SV$\mathrm{OOA}$ ), and $\mathrm{CO}_{2}^{+}$, characteristic of low volatility oxygenated organic aerosol (LV-OOA). The amount of $\mathrm{C}_{2} \mathrm{H}_{3} \mathrm{O}^{+}$in the particle mass spectra increases faster than $\mathrm{CO}_{2}^{+}$and shows a much greater decrease than $\mathrm{CO}_{2}^{+}$as the experiment progresses. There is a slight decrease in $\mathrm{CO}_{2}^{+}$at longer irradiation times, and it is possible that the uptake of low volatility species is not completely irreversible, allowing for some evaporation.

Evaporation of particles is characterized by a shift of the $D_{\mathrm{p}}$ at the maximum of the size distribution to smaller size. This shift was not observed in the aging experiments, as shown in the bottom panel of Fig. 7 where $D_{\mathrm{p}}$ increased slightly after the peak organic loading was attained around $12 \mathrm{~h}$. The two main processes affecting the particle size distribution in chamber experiments are gas-particle partitioning and wall loss. In the Caltech chambers, wall loss rates are at a minimum for particles of diameters between 200 and $300 \mathrm{~nm}$ (Fig. 1). During the aging experiments, the $D_{\mathrm{p}}$ at the size distribution maximum is below the $200-300 \mathrm{~nm}$ minimum in wall loss. If evaporation is occurring, the rate of wall loss will increase as particles get smaller. As a result, the greater loss of small particles will cause size distribution, characterized by the $D_{\mathrm{p}}$ at its maximum, to shift slightly toward the $200-300 \mathrm{~nm}$ minimum in wall loss rate. Both the evaporation and wall loss processes are slow; therefore, the 


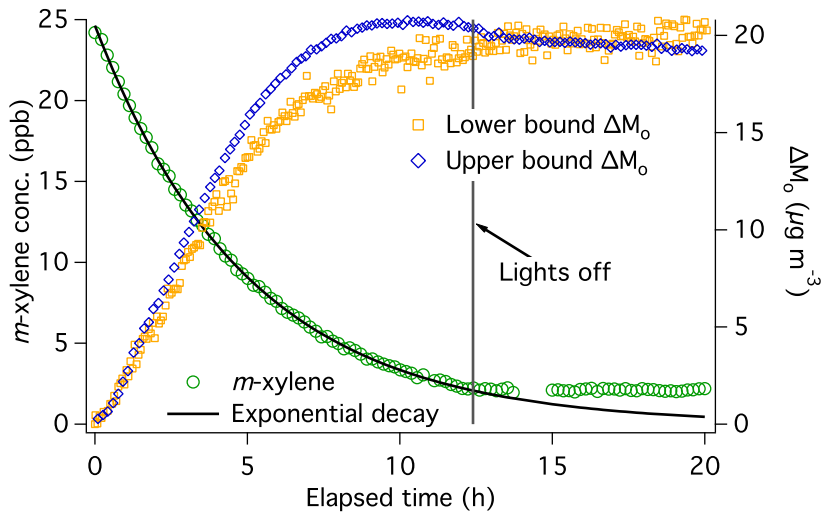

Fig. 9. Trends in $m$-xylene concentration (left axis) and $\Delta M_{\mathrm{O}}$ (right axis) when irradiation is stopped once peak $\Delta M_{\mathrm{O}}$ is attained.

two processes will tend to counteract each other with respect to their effects on the dynamics of the aerosol size distribution, and no change in $D_{\mathrm{p}}$ at the maximum of the size distribution is observed. It is also possible that the upper bound wall loss correction over-predicts the amount of evaporation occurring (see Sect. 3.4). In this case, the $D_{\mathrm{p}}$ at the size distribution maximum would only be expected to increase slightly toward the $200-300 \mathrm{~nm}$ minimum in wall loss rate.

To determine the extent to which photochemical processes are affecting the aerosol after peak growth, an experiment was performed in which the lights were turned off after $12.4 \mathrm{~h}$ of irradiation (Fig. 9). Production of $\mathrm{OH}$ ceases, and shortly thereafter, $\mathrm{OH}$ is no longer present in the chambers. The $m$ xylene concentration stabilizes after lights are turned off, and the substantial decrease in the upper bound $\Delta M_{\mathrm{o}}$ is not observed with the lights off. The lower bound $\Delta M_{\mathrm{O}}$ increases after lights are turned off to result in a $5 \%$ change in mass after $8 \mathrm{~h}$. This increase could be the result of uncertainty induced by the wall loss correction or condensation of vapors as the chamber cooled after irradiation stopped from $24^{\circ} \mathrm{C}$ to $19^{\circ} \mathrm{C}$ during hours 12.4 to 16 . The latter process is not observed in the upper bound $\Delta M_{\mathrm{o}}$, but condensation could be masked by uncertainty in the wall loss correction method, discussed in Sect. 3.4. Despite the potential uncertainties of the wall loss correction and the cooling of the chamber, the decrease observed in the lower bound $\Delta M_{\mathrm{o}}$ in the 36-h aging experiment is not observed after irradiation ceases. After the lights are turned off, the chemical composition of the particles also stops changing significantly. This is shown in $f_{44}-$ $f_{43}$ space in Fig. 10. While the aerosol forms, $f_{43}$ decreases and $f_{44}$ increases; however, after the lights are turned off, the rates of change of both $f_{43}$ and $f_{44}$ decrease substantially. In the absence of irradiation, a semivolatile species in the gas phase, $\mathrm{A}^{\mathrm{g}}$, can partition to and from particles or be lost to the walls (Fig. 8). After irradiation stops, the rate of change in the amount and composition of the particles decreases substantially; therefore, no significant repartitioning is occur-

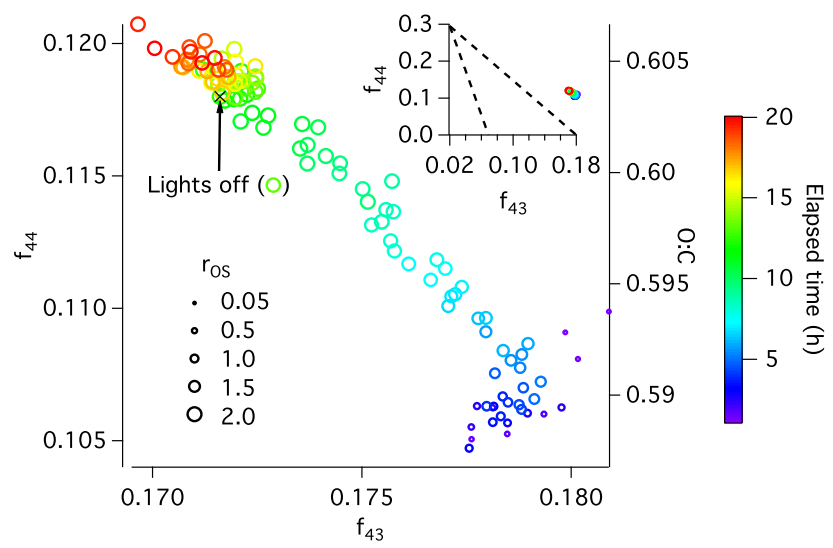

Fig. 10. Evolution of $f_{43}, f_{44}$, and O:C of $m$-xylene SOA. Irradiation was stopped after $12.4 \mathrm{~h}$, corresponding to the peak of $\Delta M_{\mathrm{O}}$. This point is denoted by the " $\mathrm{x}$ ". Marker size denotes the organicto-sulfate ratio, $r_{\mathrm{OS}}$, of suspended particles. After irradiation stops, the chemical composition of the SOA does not change significantly. The inset shows the position of the data with respect to the triangular region characteristic of ambient SOA bounded by the dashed lines, as defined by $\mathrm{Ng}$ et al. (2010).

ring. Under these conditions, only vapor phase wall loss is expected to cause repartitioning; therefore, vapor phase wall loss is not significant in this system. If minimal repartitioning is observed without irradiation, and if there are no substantial vapor phase wall losses, then repartitioning must be driven by photochemical processes that affect the chemical composition of the gases and SOA.

It was not possible to distinguish among the photochemical process occurring: reaction of $\mathrm{OH}$ with semivolatiles; reaction of $\mathrm{OH}$ with particles; and photolysis of semivolatiles. The photochemical model described in Appendix A was used to estimate lifetimes for $\mathrm{OH}$ against reaction with particles, $\mathrm{OH}$ against reaction with semivolatiles, semivolatiles against reaction with $\mathrm{OH}$, and semivolatiles against photolysis. The lifetime of $\mathrm{OH}$ against reaction with gas-phase species $\mathrm{A}^{\mathrm{g}}$, $\tau_{\mathrm{OH}+\mathrm{A}}(\mathrm{s})$, is

$\tau_{\mathrm{OH}+\mathrm{A}}=\frac{1}{k_{\mathrm{A}+\mathrm{OH}} c_{\mathrm{A}}}$

where $k_{\mathrm{A}+\mathrm{OH}}\left(\mathrm{cm}^{3} \mathrm{molec}^{-1} \mathrm{~s}^{-1}\right)$ is the reaction rate constant and $c_{\mathrm{A}}\left(\operatorname{molec} \mathrm{cm}^{-3}\right)$ is the gas-phase concentration of A. Using the combined concentrations of species $\mathrm{ROOH}, \mathrm{ROHOH}, \mathrm{ROHOOH}$, and EPOXOOH and an average rate constant $k_{\mathrm{OH}}=1 \times 10^{-10} \mathrm{~cm}^{3} \mathrm{molec}^{-1} \mathrm{~s}^{-1}(\mathrm{Ta}-$ ble 3 ), $\tau_{\mathrm{OH}+\mathrm{A}} \cong 0.2 \mathrm{~s}$. The heterogeneous reaction of $\mathrm{OH}$ with a particle surface is assumed to be pseudo-first order in terms of $\mathrm{OH}$ (Seinfeld and Pandis, 2006). The characteristic time for this process, $\tau_{\mathrm{OH}+\mathrm{P}}(\mathrm{s})$, can be calculated by:

$\tau_{\mathrm{OH}+\mathrm{P}}=\frac{1}{\frac{1}{4} \gamma \overline{\overline{\mathrm{OH}}_{\mathrm{O}}} A_{\mathrm{p}}}$ 
Table 3. Rate constants for the photochemical model.

\begin{tabular}{ll}
\hline $\begin{array}{l}\text { Rate constant } \\
\left(\mathrm{cm}^{3} \mathrm{molec}^{-1} \mathrm{~s}^{-1}\right)\end{array}$ & Source \\
\hline$j_{\mathrm{H}_{2} \mathrm{O}_{2}}=2.9 \times 10^{-6}\left(\mathrm{~s}^{-1}\right)$ & Sander et al. (2011) \\
$k_{1}=1.8 \times 10^{-12}$ & Sander et al. (2011) \\
$k_{2}=2.31 \times 10^{-11}$ & Calvert et al. (2002) \\
$k_{3}=9.8 \times 10^{-13}$ & Birdsall et al. (2010) \\
$k_{4}=1.96 \times 10^{-11}$ & MCM (Jenkin et al., 2003, \\
& Bloss et al., 2005) \\
$k_{5}=8.02 \times 10^{-11}$ & MCM \\
$j_{\mathrm{EPOX}}=1.24 \times 10^{-4}\left(\mathrm{~s}^{-1}\right)$ & MCM and Sander et al. (2011) \\
$k_{6}=9.1 \times 10^{-11}$ & MCM \\
$k_{7}=1.17 \times 10^{-10}$ & MCM \\
$j_{\mathrm{ROOH}}=2.1 \times 10^{-6}\left(\mathrm{~s}^{-1}\right)$ & Sander et al. (2011) \\
$k_{8}=1.96 \times 10^{-11}$ & MCM \\
$k_{9}=7.41 \times 10^{-11}$ & MCM \\
$k_{10}=1.96 \times 10^{-11}$ & MCM \\
$k_{11}=1.13 \times 10^{-10}$ & MCM \\
$k_{12}=2.05 \times 10^{-10}$ & MCM \\
$k_{13}=1.4 \times 10^{-12}$ & Sander et al. (2011) \\
$k_{14}=1.1 \times 10^{-10}$ & Sander et al. (2011) \\
\hline
\end{tabular}

where $\gamma$ is an uptake coefficient, here assumed to be $1, A_{\mathrm{p}}$ $\left(\mathrm{cm}^{2} \mathrm{~cm}^{-3}\right)$ is the surface area concentration of the particles, and $\overline{c_{\mathrm{OH}}}\left(\mathrm{cm} \mathrm{s}^{-1}\right)$ is given by

$\overline{c_{\mathrm{OH}}}=\left(\frac{8 R T}{\pi \mathrm{MW}_{\mathrm{OH}}}\right)^{\frac{1}{2}}$

where $T(\mathrm{~K})$ is temperature and $\mathrm{MW}$ OH $\left(\mathrm{kg} \mathrm{mol}^{-1}\right)$ is the molecular weight of $\mathrm{OH}$. The particle surface area was calculated from measured particle number distributions. Based on the upper and lower bound wall loss corrections, $\tau_{\mathrm{OH}+\mathrm{P}}$ ranges from 6-13.5 s, corresponding to particle surface areas of $(0.47-1.1) \times 10^{-5} \mathrm{~cm}^{2} \mathrm{~cm}^{-3}$.

Some of the semivolatile species used to determine $\tau_{\mathrm{OH}+\mathrm{A}}$ can also photolyze. The lifetimes of these species, $\mathrm{ROOH}$, $\mathrm{ROHOOH}$, and $\mathrm{EPOXOOH}$, against $\mathrm{OH}$ reaction and photolysis was also calculated to determine if photolysis is expected to be a large sink of gas-phase species. The lifetime of these species against reaction with $\mathrm{OH}, \tau_{\mathrm{A}+\mathrm{OH}}(\mathrm{s})$, is

$\tau_{\mathrm{A}+\mathrm{OH}}=\frac{1}{k_{\mathrm{A}+\mathrm{OH}} c_{\mathrm{OH}}}$

where $c_{\mathrm{OH}}\left(\right.$ molec $\left.\mathrm{cm}^{-3}\right)$ is the $\mathrm{OH}$ concentration, which was estimated to be $2.5 \times 10^{6}$ molec $\mathrm{cm}^{-3}$ from the measured $\mathrm{m}$ xylene decay. Under this condition, $\tau_{\mathrm{A}+\mathrm{OH}}=4.0 \times 10^{4} \mathrm{~s}$. The lifetime of these species against photolysis, $\tau_{\mathrm{A}+h v}$, is calculated by:

$\tau_{\mathrm{A}+h v}=\frac{1}{j_{\mathrm{ROOH}}}$ where $j_{\mathrm{ROOH}}$ is the photolysis rate constant of an organic peroxide, as described in Appendix A. The characteristic lifetime against photolysis is estimated as $4.7 \times 10^{5} \mathrm{~s}$. Photolysis is an order of magnitude slower than reaction with $\mathrm{OH}$, and photolysis is not expected to be a major sink of gas-phase species. Changes in particle composition are likely driven by continued oxidation of the gas phase, although $\mathrm{OH}$ reaction with particle surfaces cannot be categorically dismissed.

The continued oxidation of semivolatile species is apparent upon examination of possible gas-phase $m$-xylene oxidation products using the CIMS (Fig. 11). The top panel shows the time trace of $m / z 207$, which has the same $m / z$ as the predicted reagent ion clustering of first-generation oxidation products $\mathrm{ROH}(\mathrm{MW}+85)$ and $\mathrm{ROOH}(\mathrm{MW}+19)$ in the model (Table 4). This $\mathrm{m} / \mathrm{z}$ signal increases rapidly and peaks at 3-4 h of irradiation. When lights are turned off during the experiment, the decay slows significantly. The middle panel shows the time trace of $m / z 223$, which has the same $m / z$ as the predicted reagent ion clustering of second-generation oxidation products $\mathrm{ROHOH}(\mathrm{MW}+85)$, $\mathrm{ROHOOH}(\mathrm{MW}+19)$, and EPOXOOH (MW+19). Again, this $m / z$ signal increases rapidly and peaks slightly later at $4-5 \mathrm{~h}$ irradiation. When the lights are turned off, the signal stabilizes. The photochemical model predicts the peak of the first generation product concentrations to occur about an hour before that of the second generation product concentrations, and the time difference between the peak of the CIMS signals at $\mathrm{m} / \mathrm{z} 207$ and $\mathrm{m} / \mathrm{z}$ 223 is consistent with the model output. The bottom panel shows the time trace of $m / z 271$, which has the same $m / z$ as the predicted reagent ion clustering of third-generation oxidation product $(\mathrm{MW}+85)$ formed by the $\mathrm{EPOXOOH}+\mathrm{OH}$ reaction $\left(\operatorname{prod}_{\mathrm{EPOXOOH}+\mathrm{OH}}\right.$ in the model). From model predictions, this compound with predicted reagent ion clustering at $m / z 271$ should form more slowly. The signal at $m / z 271$ peaks at $13-14 \mathrm{~h}$ of irradiation and does not decrease after irradiation ceases. The behavior of these signals is consistent with multiple generations of oxidation. The changes are clearly photochemically driven. Vapor-phase wall loss is not a significant sink of compounds contributing to these signals, indicated by the absence of decay after the lights are turned off.

\subsection{Role of organic-to-sulfate ratio in particle wall loss corrections}

The partitioning behavior of SOA precursors affects how these species condense onto a particle size distribution (Riipinen et al., 2011). If condensation is limited by diffusion, which is typically the case for essentially non-volatile compounds, the rate of condensation depends on the surface area of the particle size distribution (Seinfeld and Pandis, 2006); in that case the organic growth tends to occur on particles with smaller $D_{\mathrm{p}}$ as this is the particle size regime where the surface area is greatest. For organics exhibiting diffusionlimited behavior, organic condensation on AS seed particles 
Table 4. Compounds represented in the photochemical model.

Compound

tends to form organic and sulfate mass distributions such that mean $D_{\mathrm{p}}$ of the organic mass distribution is smaller than that of the sulfate distribution. If condensation is controlled by gas-particle partitioning equilibrium, which is typically the case for semi-volatile compounds, these species will tend to condense preferentially into the particle size range where the mass concentration is greatest, i.e. a majority of the organic growth will occur on particles with larger $D_{\mathrm{p}}$ (Zhang et al., 2011). In this case, the organic mass distribution will peak at a larger $D_{\mathrm{p}}$ than the sulfate mass distribution. Because information about the organic and sulfate mass distributions was not available for the present experiments, a simulation was performed to assess the effects of different shapes of organic and sulfate mass distributions on the upper bound wall loss correction method.

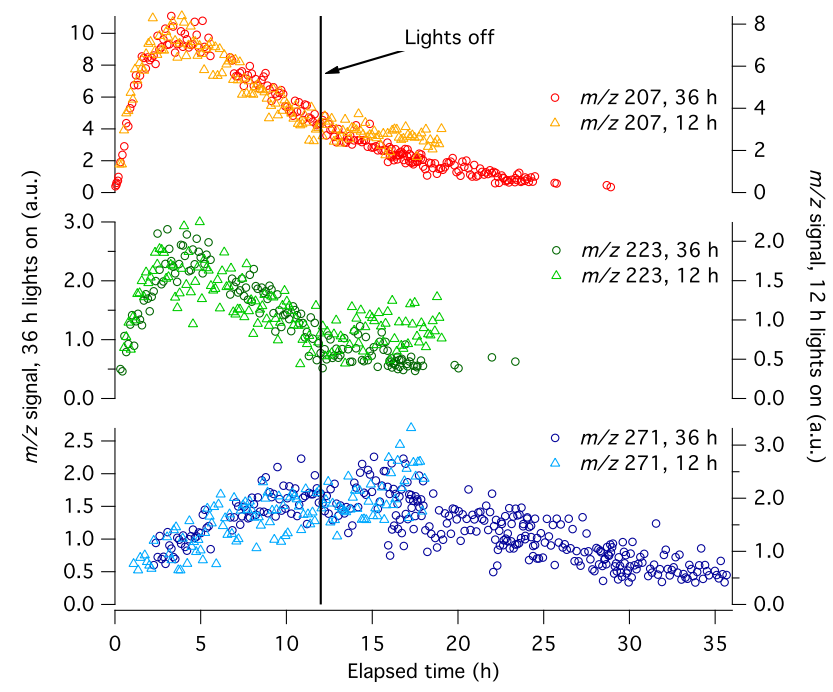

Fig. 11. Time evolution of products formed during $m$-xylene oxidation detected by the CIMS. The signals labeled $36 \mathrm{~h}$ were recorded during the set of experiments in which the chamber contents were irradiated for $36 \mathrm{~h}$. The signals labeled $12 \mathrm{~h}$ were recorded during the experiment in which the lights were turned off after $12.4 \mathrm{~h}$ of irradiation and remained off for the remainder of the experiment.

Three different pairs of organic and sulfate mass distributions consistent with the measured number distribution and $r_{\mathrm{OS}}$ were created from the suspended particle number distribution averaged between hours 12 and 12.5 of irradiation from the combined $36 \mathrm{~h}$ aging experiment in order to determine the uncertainty in the upper bound wall loss correction induced by size-dependent $r_{\mathrm{OS}}$ (Fig. 12). The peak of the measured aerosol number distribution occurs at a $D_{\mathrm{p}}$ smaller than that at which the wall loss rate is at its minimum, and the wall loss rate increases moving from lower $D_{\mathrm{p}}$ to higher $D_{\mathrm{p}}$ across the measured number distribution (not shown). Each of the distributions in Fig. 12 is characterized by the same total particle number distribution, an $r_{\mathrm{OS}}$ of 2.00 , and an organic mass concentration of $22.7-22.8 \mu \mathrm{g} \mathrm{m}^{-3}$. Case I represents condensation resulting from equilibrium gas-particle partitioning, and Case III represents condensation resulting from diffusion-limited growth. In Case II all particles have the same $r_{\mathrm{OS}}$.

The aerosol size distribution was subjected to $24 \mathrm{~h}$ of wall loss at the rates applied to the experimental number distributions, ignoring condensation (growth and evaporation are assumed to cease) and coagulation. For each of the cases, $r_{\mathrm{OS}}$ of the suspended particles and the upper bound wall-loss corrected mass concentration were calculated as a function of time (Fig. 13). In Case I, $r_{\mathrm{OS}}$ of suspended particles increased by about $10 \%$ over $24 \mathrm{~h}$ as particles with a lower $r_{\mathrm{OS}}$ were preferentially lost to the walls. Because $r_{\mathrm{OS}}$ of suspended particles is higher than that of deposited particles, using $r_{\mathrm{OS}}$ of suspended particles to represent deposited 


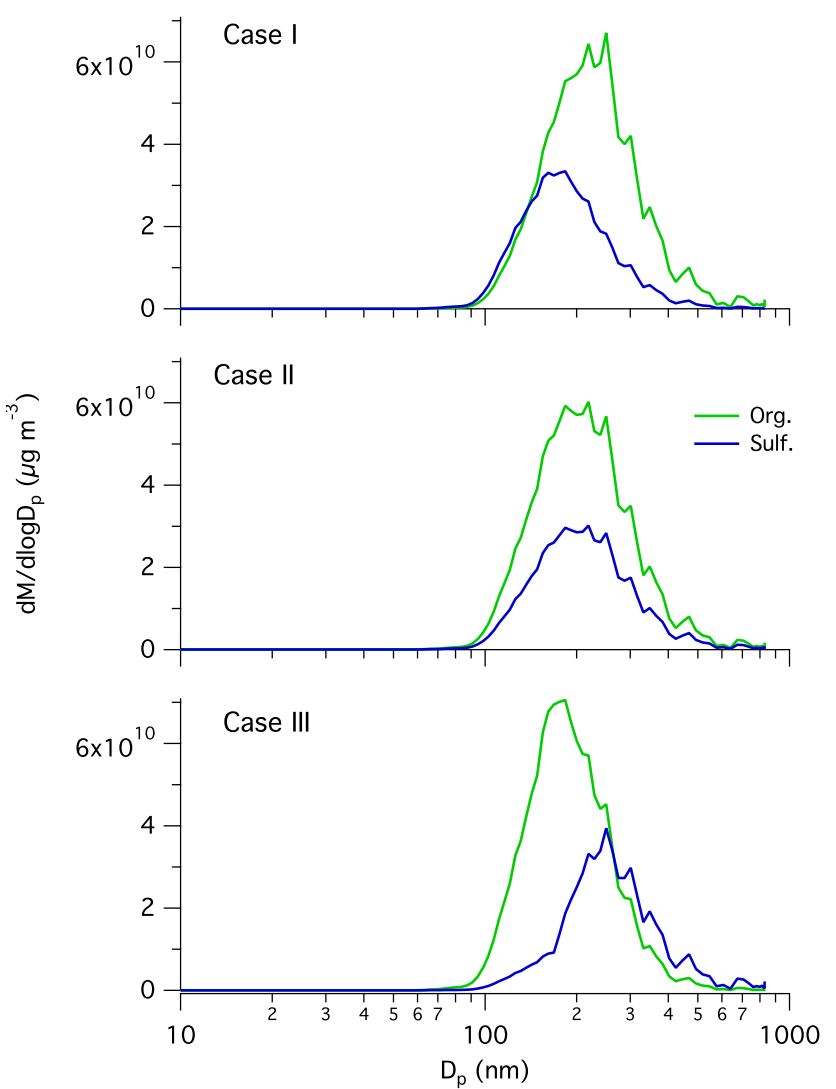

Fig. 12. Organic and sulfate mass distributions used in a simulation to assess the effect of size-dependent $r_{\mathrm{OS}}$ on the upper bound organic mass wall loss correction. All mass distributions are derived from the same observed particle number distribution and have $r_{\mathrm{OS}}$ of 2.00 and an organic mass concentration of $22.7-22.8 \mu \mathrm{g} \mathrm{m}^{-3}$. Case I is representative of condensation governed by gas-particle equilibrium partitioning (see text), and Case III is representative of condensation governed by diffusion-limited growth (see text). In Case II, $r_{\mathrm{OS}}$ is constant for all $D_{\mathrm{p}}$.

particles leads to an overestimation of organic mass lost to the walls. The over-prediction of wall-loss corrected organic mass concentration is about $10 \%$. In Case II, $r_{\mathrm{OS}}$ of suspended and deposited particles are the same by definition, and the predicted wall-loss corrected organic mass was estimated properly. In Case III $r_{\mathrm{OS}}$ of deposited particles is greater than that of suspended particles, and $r_{\mathrm{OS}}$ of suspended particles decreased by about $10 \%$ over $24 \mathrm{~h}$ because particles with a higher $r_{\mathrm{OS}}$ were preferentially lost to the walls. This resulted in an under-prediction of wall-loss corrected organic mass concentration by about $10 \%$.

Organic and sulfate mass distributions have been reported for toluene SOA condensed onto AS seed and are indicative of diffusion-limited condensation (Hildebrandt et al., 2009). If $m$-xylene SOA formation occurs by processes similar to those of toluene, the mass distributions during the present experiments will most closely resemble Case III, and increas-
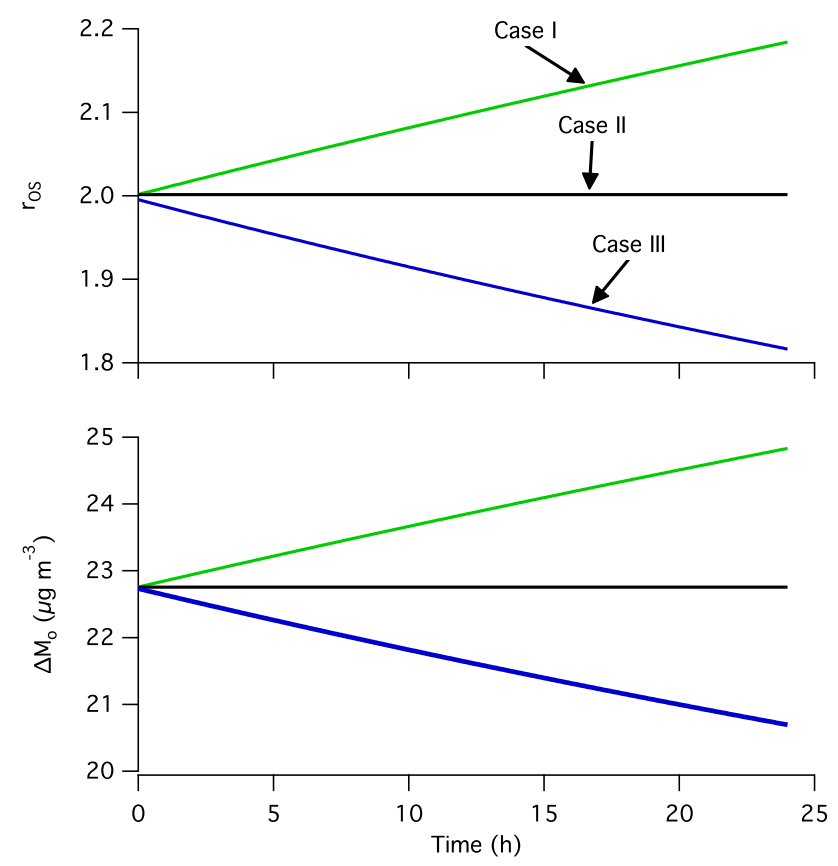

Fig. 13. Effect of $24 \mathrm{~h}$ of wall loss on the mass distributions in Fig. 12. The top panel shows the suspended particle organic-tosulfate ratio, $r_{\mathrm{OS}}$, as a function of time for each case, and the bottom panel shows the upper bound wall-loss corrected organic mass concentration as a function of time for each case.

ing under-prediction of the upper bound wall-loss corrected organic mass concentration may occur with time. During the $36 \mathrm{~h}$ combined aging experiments, the measured $r_{\mathrm{OS}}$ of suspended particles decreased from 2.1 to 1.9 between hours 12.4 and 20 and continued to decrease linearly to 1.4 at $36 \mathrm{~h}$. Between hours 12.4 and 20, the wall-loss corrected organic mass concentration decreased from 32.8 to $30 \mu \mathrm{g} \mathrm{m}^{-3}$. By hour 36 , it had decreased to $22.3 \mu \mathrm{g} \mathrm{m}^{-3}$. The changes in $r_{\mathrm{OS}}$ and mass loss can be compared to those in the experiment in which irradiation ceased after $12 \mathrm{~h}$ and in which only particle wall loss occurred after that time. Between hours 12.4 and $20, r_{\mathrm{OS}}$ decreased from 1.50 to 1.42 , and the wall-loss corrected mass concentration decreased from 20.5 to $19.2 \mu \mathrm{g} \mathrm{m}^{-3}$. The decrease in both organic-to-sulfate ratio and wall-loss corrected mass concentration in the 12-h irradiation experiment are indicative of wall loss of an aerosol size distribution characterized by diffusion-limited growth. The experimental conditions of the 36-h experiment were similar to the 12-h irradiation experiment; however, both the initial $m$-xylene concentration and the seed volume concentration in the 12-h irradiation experiment were lower than those in the combined 36-h aging experiments, and $r_{\mathrm{OS}}$ is expected to differ as a result. Despite the differences, it is expected that the size distribution of the suspended particles in hours 12.4-20 during 36-h experiment should behave similarly to the size distribution of particles during hours $12.4-20$ of the 
12-h irradiation experiment if only particle wall loss is occurring. The fractional decrease in $r_{\mathrm{OS}}$ during hours $12.4-20$ of the 36-h irradiation experiment is approximately double that of the 12-h irradiation experiment, suggesting that an additional process besides particle wall loss, such as gas-particle repartitioning due to evaporation, affected the suspended particle $r_{\mathrm{OS}}$. The magnitude of evaporation, however, may not be as large as originally thought due to uncertainty in the upper bound wall loss correction method.

The lower bound wall loss correction should be unaffected by size-dependent $r_{\mathrm{OS}}$ distributions. The number and size of deposited particles is calculated independently of particle composition and is added back to the number distribution of suspended particles to calculate the total volume of particles. In obtaining the total volume of organics, the volume of seed or other background particles is subtracted from the total volume. This calculation assumes that the seed or background particle volume does not change during an experiment.

\subsection{Acidic seed effects}

Aging experiments were also performed using acidic MS + SA seed to determine the extent to which particle acidity affects chemical aging of $m$-xylene SOA. Figure 14 shows the elemental ratios for both AS and MS + SA seeded experiments. No difference between the acidic and neutral seeds for $m$-xylene-derived SOA is observed. $\mathrm{Ng}$ et al. (2007) did not observe a difference in yields for low- $\mathrm{NO}_{\mathrm{x}} m$-xylene SOA with neutral and acidic seed particles; therefore, it is plausible that the chemical composition of the aerosol condensed onto the two types of seed particles is similar.

\section{Conclusions}

Laboratory chamber studies provide fundamental information on the mechanisms of formation of SOA. The duration of chamber experiments is limited by several factors, including wall loss of particles and vapors and depletion of chamber air through instrument sampling. Laboratory experiments attempt to approach durations of $\mathrm{OH}$ radical exposure corresponding to those of particles in the atmosphere, on the order of a week, through enhanced $\mathrm{OH}$ radical levels. In the present work we extend the duration of chamber experiments by sampling protocols that minimize the amount of chamber air removed over the course of the experiment. The protocol developed here allows experiments up to $36 \mathrm{~h}$ duration. Hydroxyl radical levels in the experiments reported here are roughly at atmospheric levels. We address SOA formation from the photooxidation of $m$-xylene, an important anthropogenic precursor to organic aerosol. The extended duration experiments provide a view into the multi-generational chemistry involved in $m$-xylene SOA formation that can be expected to be occurring in the atmosphere. Although the current work studies only low- $\mathrm{NO}_{\mathrm{x}}$ chemistry, the $m$-xylene

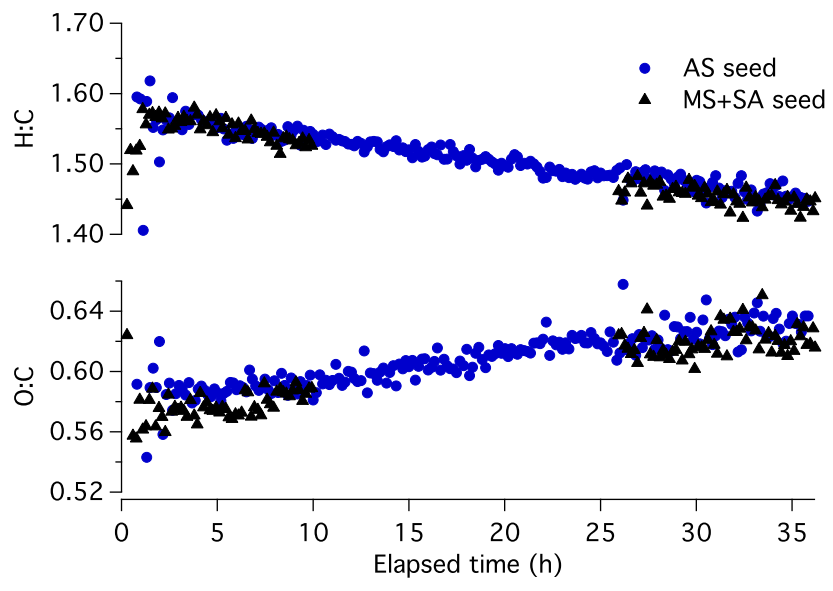

Fig. 14. Elemental ratios of $m$-xylene aerosol condensed onto neutral (AS) and acidic (MS + SA) seed particles.

oxidation mechanism leading to SOA formation under high$\mathrm{NO}_{\mathrm{x}}$ conditions is also expected to follow multi-generational chemistry (Kwok et al., 1997; Zhao et al., 2005; Ng et al., 2007; Song et al., 2007; Noda et al., 2009; Birdsall et al., 2010). The generations of oxidation of a precursor volatile organic compound can lead to functionalized products of ever decreasing volatility, characterized by increasing elemental O:C ratio, as well as to products of higher volatility that do not contribute to SOA. Based on CIMS measurements, there is strong evidence of gas-phase loss of higher generation products. That this process involves photooxidation or photolysis is confirmed by the absence of changes in total aerosol amount when irradiation is stopped. Wall loss of vapor can be excluded as the cause of this behavior. Estimates of reaction timescales suggest that gas-phase processes are most likely involved in this latter stage of aging, although direct $\mathrm{OH}$ reaction with the surface of the particles cannot be ruled out. Finally, the present work offers a protocol for laboratory chamber experiments to attain times approaching more closely those of atmospheric aerosol residence times.

\section{Appendix A}

\section{Photochemical model}

To estimate both $\mathrm{OH}$ concentration and the importance of $\mathrm{OH}$ reaction with later-generation oxidation products, a photochemical model (Reactions R1-R23 below) was constructed. Products through three generations of oxidation are included. Primary oxidation products are those suggested by Birdsall et al. (2010) and Zhao et al. (2005) with product yields and further oxidative pathways as derived from the MCM (Jenkin et al., 2003; Bloss et al., 2005). Values of rate constants are listed in Table 3, and compounds represented in the model are given in Table 4. Photolysis rate constants are calculated using the irradiance spectrum measured for the chamber 
lights and absorption cross section values and quantum yields from Sander et al. (2011). The following reactions are included:

$$
\begin{aligned}
& \mathrm{H}_{2} \mathrm{O}_{2}+h v \stackrel{\mathrm{j}_{2} \mathrm{O}_{2}}{\longrightarrow} 2 \mathrm{OH} \\
& \mathrm{H}_{2} \mathrm{O}_{2}+\mathrm{OH} \stackrel{k_{1}}{\longrightarrow} \mathrm{HO}_{2}+\mathrm{H}_{2} \mathrm{O} \\
& \mathrm{RH}+\mathrm{OH} \stackrel{k_{2}}{\longrightarrow} 0.54 \mathrm{RO}_{2} \\
& \stackrel{k_{2}}{\longrightarrow} 0.29 \mathrm{EPOX}+0.29 \mathrm{HO}_{2} \\
& \stackrel{k_{2}}{\longrightarrow} 0.17 \mathrm{ROH}+0.17 \mathrm{HO}_{2} \\
& \mathrm{RO}_{2}+\mathrm{RO}_{2} \stackrel{k_{3}}{\longrightarrow} \operatorname{prod}_{\mathrm{RO}_{2}+\mathrm{RO}_{2}} \\
& \mathrm{RO}_{2}+\mathrm{HO}_{2} \stackrel{k_{4}}{\longrightarrow} \mathrm{ROOH} \\
& \mathrm{EPOX}+\mathrm{OH} \stackrel{k_{5}}{\longrightarrow} \mathrm{EPOXO}_{2} \\
& \mathrm{EPOX}+h v \stackrel{j_{\mathrm{EPOX}}}{\longrightarrow} \operatorname{prod}_{\mathrm{EPOX}+h v} \\
& \mathrm{ROH}+\mathrm{OH} \stackrel{k_{6}}{\longrightarrow} 0.51 \mathrm{ROHO}_{2} \\
& \stackrel{k_{6}}{\longrightarrow} 0.42 \mathrm{ROHOH} \\
& \stackrel{k_{6}}{\longrightarrow} 0.07 \mathrm{RO} \\
& \mathrm{ROOH}+\mathrm{OH} \stackrel{k_{7}}{\longrightarrow} \operatorname{prod}_{\mathrm{ROOH}+\mathrm{OH}}+\mathrm{OH} \\
& \mathrm{ROOH}+h v \stackrel{j_{\mathrm{ROOH}}}{\longrightarrow} \operatorname{prod}_{\mathrm{ROOH}+h v}+\mathrm{OH} \\
& \mathrm{EPOXO}_{2}+\mathrm{HO}_{2} \stackrel{k_{8}}{\longrightarrow} \mathrm{EPOXOOH} \\
& \mathrm{EPOXOOH}+\mathrm{OH} \stackrel{k_{9}}{\longrightarrow} \operatorname{prod}_{\mathrm{EPOXOOH}+\mathrm{OH}}+\mathrm{OH} \\
& \mathrm{EPOXOOH}+h v \stackrel{j_{\mathrm{ROOH}}}{\longrightarrow} \operatorname{prod}_{\mathrm{EPOXOOH}+h v}+\mathrm{OH} \\
& \mathrm{ROHO}_{2}+\mathrm{HO}_{2} \stackrel{k_{10}}{\longrightarrow} \mathrm{ROHOOH} \\
& \mathrm{ROHOOH}+\mathrm{OH} \stackrel{k_{11}}{\longrightarrow} \mathrm{ROHO}_{2} \\
& \mathrm{ROHOOH}+h v \stackrel{j_{\mathrm{ROOH}}}{\longrightarrow} \operatorname{prod}_{\mathrm{ROHOOH}+h v} \\
& \mathrm{ROHOH}+\mathrm{OH} \stackrel{k_{12}}{\longrightarrow} \operatorname{prod}_{\mathrm{ROHOH}+\mathrm{OH}} \\
& \mathrm{HO}_{2}+\mathrm{HO}_{2} \stackrel{k_{13}}{\longrightarrow} \mathrm{H}_{2} \mathrm{O}_{2}+\mathrm{O}_{2} \\
& \mathrm{OH}+\mathrm{HO}_{2} \stackrel{k_{14}}{\longrightarrow} \mathrm{H}_{2} \mathrm{O}+\mathrm{O}_{2}
\end{aligned}
$$

Neither gas-particle partitioning nor vapor-phase wall loss was included in the model because there is not sufficient information about either process to accurately represent it in the model. Vapor-phase wall loss is assumed to be minor (Fig. 11) and should not have a large effect on gas species concentrations.

Acknowledgements. This work was supported by the Office of Science (Biological and Environmental Research), US Department of Energy Grant DE-SC 0006626, and National Science Foundation Grant AGS-1057183. The CIMS instrument was purchased as part of a major research instrumentation grant from the National Science Foundation (Grant ATM-0619783); assembly and testing was supported by the Davidow Discovery Fund. We thank Katherine Schilling and ManNin Chan for experimental assistance and Arthur Chan for helpful discussion. We thank the reviewers for useful feedback on the discussions paper. Christine Loza, Lindsay Yee, and Jill Craven were supported by National Science Foundation Graduate Research Fellowships.

Edited by: N. M. Donahue

\section{References}

Aiken, A. C., DeCarlo, P. F., Kroll, J. H., Worsnop, D. R., Huffman, J. A., Docherty, K. S., Ulbrich, I. M., Mohr, C., Kimmel, J. R., Sueper, D., Sun, Y., Zhang, Q., Trimborn, A., Northway, M., Ziemann, P. J., Canagaratna, M. R., Onasch, T. B., Alfarra, M. R., Prevot, A. S. H., Dommen, J., Duplissy, J., Metzger, A., Baltensperger, U., and Jimenez, J. L.: O/C and OM/OC ratios of primary, secondary, and ambient organic aerosols with highresolution time-of-flight aerosol mass spectrometry, Environ. Sci. Technol., 42, 4478-4485, doi:10.1021/es703009q, 2008.

Balkanski, Y. J., Jacob, D. J., D. J., Gardner, G. M., Graustein, W. C., and Turekian, K. K.: Transport and residence times of tropospheric aerosols inferred from a global 3-dimensional simulation of PB-210, J. Geophys. Res-Atmos., 98, 20573-20586, doi:10.1029/93JD02456, 1993.

Birdsall, A. W., Andreoni, J. F., and Elrod, M. J.: Investigation of the role of bicyclic peroxy radicals in the oxidation mechanism of toluene, J. Phys. Chem. A, 114, 10655-10663, doi:10.1021/jp105467e, 2010.

Bloss, C., Wagner, V., Jenkin, M. E., Volkamer, R., Bloss, W. J., Lee, J. D., Heard, D. E., Wirtz, K., Martin-Reviejo, M., Rea, G., Wenger, J. C., and Pilling, M. J.: Development of a detailed chemical mechanism (MCMv3.1) for the atmospheric oxidation of aromatic hydrocarbons, Atmos. Chem. Phys., 5, 641-664, doi:10.5194/acp-5-641-2005, 2005.

Calvert, J. G., Atkinson, R., H., B. K., Kamens, R. M., Seinfeld, J. H., Wallington, T. J., and Yarwood, G.: The Mechanisms of Atmospheric Oxidation of Aromatic Hydrocarbons, Oxford University Press, New York, 2002.

Canagaratna, M. R., Jayne, J. T., Jimenez, J. L., Allan, J. D., Alfarra, M. R., Zhang, Q., Onasch, T. B., Drewnick, F., Coe, H., Middlebrook, A., Delia, A., Williams, L. R., Trimborn, A. M., Northway, M. J., DeCarlo, P. F., Kolb, C. E., Davidovits, P., and Worsnop, D. R.: Chemical and microphysical characterization of ambient aerosols with the Aerodyne aerosol mass spectrometer, Mass Spectrom. Rev., 26, 185-222, doi:10.1002/mas.20115, 2007.

Chhabra, P. S., Flagan, R. C., and Seinfeld, J. H.: Elemental analysis of chamber organic aerosol using an aerodyne high-resolution aerosol mass spectrometer, Atmos. Chem. Phys., 10, 4111-4131, doi:10.5194/acp-10-4111-2010, 2010.

Chhabra, P. S., Ng, N. L., Canagaratna, M. R., Corrigan, A. L., Russell, L. M., Worsnop, D. R., Flagan, R. C., and Seinfeld, J. H.: Elemental composition and oxidation of chamber organic aerosol, Atmos. Chem. Phys., 11, 8827-8845, doi:10.5194/acp-11-88272011, 2011.

Cocker, D. R., Flagan, R. C., and Seinfeld, J. H.: State-of-theart chamber facility for studying atmospheric aerosol chemistry, Environ. Sci. Technol., 35, 2594-2601, doi:10.1021/es0019169, 2001. 
Crounse, J. D., McKinney, K. A., Kwan, A. J., and Wennberg, P. O.: Measurement of gas-phase hydroperoxides by chemical ionization mass spectrometry, Anal. Chem., 78, 6726-6732, doi:10.1021/ac0604235, 2006.

DeCarlo, P. F., Kimmel, J. R., Trimborn, A., Northway, M. J., Jayne, J. T., Aiken, A. C., Gonin, M., Fuhrer, K., Horvath, T., Docherty, K. S., Worsnop, D. R., and Jimenez, J. L.: Field-deployable, high-resolution, time-of-flight aerosol mass spectrometer, Anal. Chem., 78, 8281-8289, doi:10.1021/ac061249n, 2006.

Hallquist, M., Wenger, J. C., Baltensperger, U., Rudich, Y., Simpson, D., Claeys, M., Dommen, J., Donahue, N. M., George, C., Goldstein, A. H., Hamilton, J. F., Herrmann, H., Hoffmann, T., Iinuma, Y., Jang, M., Jenkin, M. E., Jimenez, J. L., Kiendler-Scharr, A., Maenhaut, W., McFiggans, G., Mentel, Th. F., Monod, A., Prévôt, A. S. H., Seinfeld, J. H., Surratt, J. D., Szmigielski, R., and Wildt, J.: The formation, properties and impact of secondary organic aerosol: current and emerging issues, Atmos. Chem. Phys., 9, 5155-5236, doi:10.5194/acp-95155-2009, 2009.

Heald, C. L., Kroll, J. H., Jimenez, J. L., Docherty, K. S., DeCarlo, P. F., Aiken, A. C., Chen, Q., Martin, S. T., Farmer, D. K., and Artaxo, P.: A simplified description of the evolution of organic aerosol composition in the atmosphere, Geophys. Res. Lett., 37, L08803, doi:10.1029/2010GL042737, 2010.

Hildebrandt, L., Donahue, N. M., and Pandis, S. N.: High formation of secondary organic aerosol from the photo-oxidation of toluene, Atmos. Chem. Phys., 9, 2973-2986, doi:10.5194/acp-92973-2009, 2009.

Hildebrandt, L., Henry, K. M., Kroll, J. H., Worsnop, D. R., Pandis, S. N., and Donahue, N. M.: Evaluating the Mixing of Organic Aerosol Components Using High-Resolution Aerosol Mass Spectrometry, Environ. Sci. Technol., 45, 6329-6335, doi:10.1021/es200825g, 2011.

Jenkin, M. E., Saunders, S. M., Wagner, V., and Pilling, M. J.: Protocol for the development of the Master Chemical Mechanism, MCM v3 (Part B): tropospheric degradation of aromatic volatile organic compounds, Atmos. Chem. Phys., 3, 181-193, doi:10.5194/acp-3-181-2003, 2003.

Jimenez, J. L., Canagaratna, M. R., Donahue, N. M., Prevot, A. S. H., Zhang, Q., Kroll, J. H., DeCarlo, P. F., Allan, J. D., Coe, H., Ng, N. L., Aiken, A. C., Docherty, K. S., Ulbrich, I. M., Grieshop, A. P., Robinson, A. L., Duplissy, J., Smith, J. D., Wilson, K. R., Lanz, V. A., Hueglin, C., Sun, Y. L., Tian, J., Laaksonen, A., Raatikainen, T., Rautiainen, J., Vaattovaara, P., Ehn, M., Kulmala, M., Tomlinson, J. M., Collins, D. R., Cubison, M. J., Dunlea, E. J., Huffman, J. A., Onasch, T. B., Alfarra, M. R., Williams, P. I., Bower, K., Kondo, Y., Schneider, J., Drewnick, F., Borrmann, S., Weimer, S., Demerjian, K., Salcedo, D., Cottrell, L., Griffin, R., Takami, A., Miyoshi, T., Hatakeyama, S., Shimono, A., Sun, J. Y., Zhang, Y. M., Dzepina, K., Kimmel, J. R., Sueper, D., Jayne, J. T., Herndon, S. C., Trimborn, A. M., Williams, L. R., Wood, E. C., Middlebrook, A. M., Kolb, C. E., Baltensperger, U., and Worsnop, D. R.: Evolution of organic aerosols in the atmosphere, Science, 326, 1525-1529, doi:10.1126/science.1180353, 2009.

Keywood, M. D., Varutbangkul, V., Bahreini, R., Flagan, R. C., and Seinfeld, J. H.: Secondary organic aerosol formation from the ozonolysis of cycloalkenes and related compounds, Environ. Sci. Technol., 38, 4157-4164, doi:10.1021/es035363o, 2004.
Kroll, J. and Seinfeld, J.: Chemistry of secondary organic aerosol: Formation and evolution of low-volatility organics in the atmosphere, Atmos. Environ., 42, 3593-3624, doi:10.1016/j.atmosenv.2008.01.003, 2008.

Kroll, J. H., Smith, J. D., Che, D. L., Kessler, S. H., Worsnop, D. R., and Wilson, K. R.: Measurement of fragmentation and functionalization pathways in the heterogeneous oxidation of oxidized organic aerosol, Phys. Chem. Chem. Phys., 11, 8005-8014, doi:10.1039/b905289e, 2009.

Kwok, E., Aschmann, S., Atkinson, R., and Arey, J.: Products of the gas-phase reactions of $o$-, $m$-and $p$-xylene with the $\mathrm{OH}$ radical in the presence and absence of $\mathrm{NO}_{\mathrm{x}}$, J. Chem. Soc., Faraday Trans., 93, 2847-2854, 1997.

Lambe, A. T., Onasch, T. B., Massoli, P., Croasdale, D. R., Wright, J. P., Ahern, A. T., Williams, L. R., Worsnop, D. R., Brune, W. H., and Davidovits, P.: Laboratory studies of the chemical composition and cloud condensation nuclei (CCN) activity of secondary organic aerosol (SOA) and oxidized primary organic aerosol (OPOA), Atmos. Chem. Phys., 11, 8913-8928, doi:10.5194/acp-11-8913-2011, 2011.

Lee, A. K. Y., Herckes, P., Leaitch, W. R., Macdonald, A. M., and Abbatt, J. P. D.: Aqueous $\mathrm{OH}$ oxidation of ambient organic aerosol and cloud water organics: Formation of highly oxidized products, Geophys. Res. Lett., 38, L11805, doi:10.1029/2011GL047439, 2011.

Matthew, B. M., Middlebrook, A. M., and Onasch, T. B.: Collection efficiencies in an Aerodyne aerosol mass spectrometer as a function of particle phase for laboratory generated aerosols, Aerosol Sci. Tech., 42, 884-898, doi:10.1080/02786820802356797, 2008.

Murphy, D. M., Cziczo, D. J., Froyd, K. D., Hudson, P. K., Matthew, B. M., Middlebrook, A. M., Peltier, R. E., Sullivan, A., Thomson, D. S., and Weber, R. J.: Single-particle mass spectrometry of tropospheric aerosol particles, J. Geophys. Res-Atmos., 111, D23S23, doi:10.1029/2006JD007340, 2006.

Ng, N. L., Kroll, J. H., Chan, A. W. H., Chhabra, P. S., Flagan, R. C., and Seinfeld, J. H.: Secondary organic aerosol formation from m-xylene, toluene, and benzene, Atmos. Chem. Phys., 7, 3909-3922, doi:10.5194/acp-7-3909-2007, 2007.

Ng, N. L., Canagaratna, M. R., Zhang, Q., Jimenez, J. L., Tian, J., Ulbrich, I. M., Kroll, J. H., Docherty, K. S., Chhabra, P. S., Bahreini, R., Murphy, S. M., Seinfeld, J. H., Hildebrandt, L., Donahue, N. M., DeCarlo, P. F., Lanz, V. A., Prévôt, A. S. H., Dinar, E., Rudich, Y., and Worsnop, D. R.: Organic aerosol components observed in Northern Hemispheric datasets from Aerosol Mass Spectrometry, Atmos. Chem. Phys., 10, 46254641, doi:10.5194/acp-10-4625-2010, 2010.

Ng, N. L., Canagaratna, M. R., Jimenez, J. L., Chhabra, P. S., Seinfeld, J. H., and Worsnop, D. R.: Changes in organic aerosol composition with aging inferred from aerosol mass spectra, Aerosol Sci. Tech., 11, 6465-6474, doi:10.5194/acp-11-64652011, 2011.

Noda, J., Volkamer, R., and Molina, M. J.: Dealkylation of alkylbenzenes: a significant pathway in the toluene, $o-, m-, p$ xylene $+\mathrm{OH}$ reaction, J. Phys. Chem. A, 113, 9658-9666, doi:10.1021/jp901529k, 2009.

Paulot, F., Crounse, J. D., Kjaergaard, H. G., Kurten, A., St Clair, J. M., Seinfeld, J. H., and Wennberg, P. O.: Unexpected epoxide formation in the gas-phase photooxidation of isoprene, Science, 
325, 730-733, doi:10.1126/science.1172910, 2009.

Qi, L., Nakao, S., Malloy, Q., Warren, B., and Cocker, D. R.: Can secondary organic aerosol formed in an atmospheric simulation chamber continuously age?, Atmos. Environ., 44, 2990-2996, doi:10.1016/j.atmosenv.2010.05.020, 2010.

Riipinen, I., Pierce, J. R., Yli-Juuti, T., Nieminen, T., Häkkinen, S., Ehn, M., Junninen, H., Lehtipalo, K., Petäjä, T., Slowik, J., Chang, R., Shantz, N. C., Abbatt, J., Leaitch, W. R., Kerminen, V.-M., Worsnop, D. R., Pandis, S. N., Donahue, N. M., and Kulmala, M.: Organic condensation: a vital link connecting aerosol formation to cloud condensation nuclei (CCN) concentrations, Atmos. Chem. Phys., 11, 3865-3878, doi:10.5194/acp-11-38652011, 2011.

Rudich, Y., Donahue, N. M., and Mentel, T. F.: Aging of organic aerosol: Bridging the gap between laboratory and field studies, Annu. Rev. Phys. Chem., 58, 321-352, doi:10.1146/annurev.physchem.58.032806.104432, 2007.

Sander, S. P., Abbatt, J., Barker, J. R., Burkholder, J. B., Friedl, R. R., Golden, D. M., Huie, R. E., Kolb, C. E., J., K. M., Moortgat, G. K., Orkin, V. L., and Wine, P. H.: Chemical kinetics and photochemical data for use in atmospheric studies, Evaluation No. 17. JPL Publication 10-6, Jet Propulsion Laboratory, Pasadena, http://jpldataeval.jpl.nasa.gov, 2011.

Seinfeld, J. H. and Pandis, S. N.: Atmospheric Chemistry and Physics, John Wiley and Sons, Inc., Hoboken, NJ, second edn., 2006.

Shilling, J. E., Chen, Q., King, S. M., Rosenoern, T., Kroll, J. H., Worsnop, D. R., DeCarlo, P. F., Aiken, A. C., Sueper, D., Jimenez, J. L., and Martin, S. T.: Loading-dependent elemental composition of $\alpha$-pinene SOA particles, Atmos. Chem. Phys., 9, 771-782, doi:10.5194/acp-9-771-2009, 2009.

Shiraiwa, M., Ammann, M., Koop, T., and Pöschl, U.: Gas uptake and chemical aging of semisolid organic aerosol particles, Proc. Natl. Acad. Sci. USA, 108, 11003-11008, doi:10.1073/pnas.1103045108, 2011.

Song, C., Na, K., Warren, B., Malloy, Q., and Cocker, D. R.: Secondary organic aerosol formation from $m$-xylene in the absence of $\mathrm{NO}_{\mathrm{x}}$, Environ. Sci. Technol., 41, 7409-7416, doi:10.1021/es070429r, 2007.

St. Clair, J. M., McCabe, D. C., Crounse, J. D., Steiner, U., and Wennberg, P. O.: Chemical ionization tandem mass spectrometer for the in situ measurement of methyl hydrogen peroxide, Rev. Sci. Instrum., 81, 094102, doi:10.1063/1.3480552, 2010.
Vaden, T. D., Song, C., Zaveri, R. A., Imre, D., and Zelenyuk, A.: Morphology of mixed primary and secondary organic particles and the adsorption of spectator organic gases during aerosol formation, P. Natl. Acad. Sci. USA, 107, 6658-6663, doi:10.1073/pnas.0911206107, 2010.

Vaden, T. D., Imre, D., Beránek, J., Shrivastava, M., and Zelenyuk, A.: Evaporation kinetics and phase of laboratory and ambient secondary organic aerosol, P. Natl. Acad. Sci. USA, 108, 21902195, doi:10.1073/pnas.1013391108, 2011.

Virtanen, A., Joutsensaari, J., Koop, T., Kannosto, J., Yli-Pirilä, P., Leskinen, J., Mäkelä, J. M., Holopainen, J. K., Pöschl, U., Kulmala, M., Worsnop, D. R., and Laaksonen, A.: An amorphous solid state of biogenic secondary organic aerosol particles, Nature, 467, 824-827, doi:10.1038/nature09455, 2010.

Weitkamp, E. A., Sage, A. M., Pierce, J. R., Donahue, N. M., and Robinson, A. L.: Organic Aerosol Formation from Photochemical Oxidation of Diesel Exhaust in a Smog Chamber, Environ. Sci. Technol., 41, 6969-6975, doi:10.1021/es070193r, 2007.

Zhang, Q., Jimenez, J. L., Canagaratna, M. R., Allan, J. D., Coe, H., Ulbrich, I., Alfarra, M. R., Takami, A., Middlebrook, A. M., Sun, Y. L., Dzepina, K., Dunlea, E., Docherty, K., DeCarlo, P. F., Salcedo, D., Onasch, T., Jayne, J. T., Miyoshi, T., Shimono, A., Hatakeyama, S., Takegawa, N., Kondo, Y., Schneider, J., Drewnick, F., Borrmann, S., Weimer, S., Demerjian, K., Williams, P., Bower, K., Bahreini, R., Cottrell, L., Griffin, R. J., Rautiainen, J., Sun, J. Y., Zhang, Y. M., and Worsnop, D. R.: Ubiquity and dominance of oxygenated species in organic aerosols in anthropogenically-influenced Northern Hemisphere midlatitudes, Geophys. Res. Lett., 34, L13801, doi:10.1029/2007GL029979, 2007.

Zhang, X., Pandis, S. N., and Seinfeld, J. H.: Aerosol condensation: Diffusion limited vs quasi-equilibrium growth, Aerosol Sci Technol., submitted, 2011.

Zhao, J., Zhang, R., Misawa, K., and Shibuya, K.: Experimental product study of the $\mathrm{OH}$-initiated oxidation of $m$-xylene, J. Photoch. Photobio. A, 176, 199-207, doi:10.1016/j.jphotochem.2005.07.013, 2005. 